\title{
AC electrokinetic induced non-Newtonian electrothermal blood flow in 3D microfluidic biosensor with ring electrodes for point-of- care diagnostics
}

Cite as: J. Appl. Phys. 126, 084501 (2019); https://doi.org/10.1063/1.5099272

Submitted: 09 April 2019 . Accepted: 25 July 2019 . Published Online: 23 August 2019

Qinlong Ren, Yichao Wang, Xixiang Lin, and Cho Lik Chan
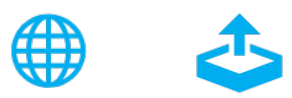

\section{ARTICLES YOU MAY BE INTERESTED IN}

Formation of nitrogen-vacancy centers in $4 \mathrm{H}-\mathrm{SiC}$ and their near infrared photoluminescence properties

Journal of Applied Physics 126, 083105 (2019); https://doi.org/10.1063/1.5099327

Defect-rich GaN interlayer facilitating the annihilation of threading dislocations in polar GaN crystals grown on (0001)-oriented sapphire substrates

Journal of Applied Physics 126, 085301 (2019); https://doi.org/10.1063/1.5092284

Fluorescence microscopy of biophysical protein dynamics in nanoporous hydrogels

Journal of Applied Physics 126, 081101 (2019); https://doi.org/10.1063/1.5110299

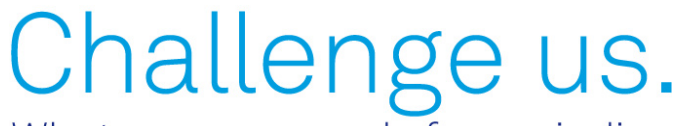

What are your needs for periodic signal detection?

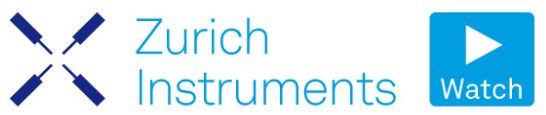

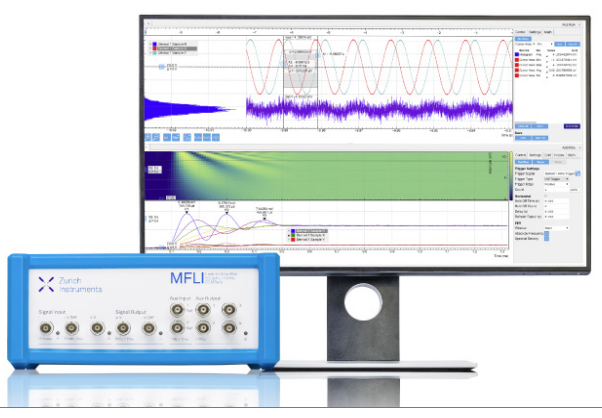

126, 084501 


\title{
AC electrokinetic induced non-Newtonian electrothermal blood flow in 3D microfluidic biosensor with ring electrodes for point-of-care diagnostics
}

Cite as: J. Appl. Phys. 126, 084501 (2019); doi: 10.1063/1.5099272

Submitted: 9 April 2019 . Accepted: 25 July 2019 .

Published Online: 23 August 2019

Qinlong Ren, ${ }^{1, \text { a) }}$ Yichao Wang, ${ }^{2}$ Xixiang Lin, ${ }^{1}$ and Cho Lik Chan ${ }^{3}$

\author{
AFFILIATIONS \\ ${ }^{\top}$ Key Laboratory of Thermo-Fluid Science and Engineering of MOE, School of Energy and Power Engineering, Xi'an Jiaotong \\ University, Xi'an, Shaanxi 710049, China \\ ${ }^{2}$ Department of Computer Science and Technology, School of Electronic and Information Engineering, Xi'an Jiaotong University, \\ Xi'an, Shaanxi 710049, China \\ ${ }^{3}$ Department of Aerospace and Mechanical Engineering, The University of Arizona, Tucson, Arizona 85721, USA
}

\begin{abstract}
${ }^{\text {a) }}$ Author to whom correspondence should be addressed: qinlongren@xjtu.edu.ch
ABSTRACT

Efficient pumping of whole blood is an essential task in biomedical engineering, especially for point-of-care diagnostics using lab-on-a-chip devices. Alternating current (AC) electrokinetics have been widely used for several different applications among which pumping fluids using the precisely controlled electric field without any moving mechanical parts is significant. Due to its high conductive characteristic, it is difficult to drive the blood flow using the $\mathrm{AC}$ electroosmosis phenomenon because the electric double layer is highly compressed. Fortunately, the AC electrothermal (ACET) phenomenon occurs due to the variation of temperature-dependent permittivity and conductivity caused by Joule heating effects or other heat sources making it powerful for driving high electrical conductivity physiological fluids in biomedical devices. Compared with Newtonian fluids like saline solutions or urine, the non-Newtonian rheological nature and AC frequencydependent dielectric property of blood make its ACET driving mechanism more complicated and attractive. In this paper, ACET induced blood flow in the 3D microfluidic channel is modeled by the lattice Boltzmann method accelerated using graphics processor units. The Carreau-Yasuda model is applied to simulate the shear-thinning behavior of blood flow, and its electrothermal pumping efficiency is investigated with respect to the AC electrode configuration, AC voltage magnitude, and AC signal frequency by comparing it with the ACET pumping of Newtonian fluids using scaling law analysis. The results demonstrate that the ACET phenomenon is effective for pumping non-Newtonian whole blood flow in microfluidic devices with ring electrodes which will contribute to the point-of-care diagnostic of bacterial bloodstream infections or rapid detection of circulating tumor cells.
\end{abstract}

Published under license by AIP Publishing. https://doi.org/10.1063/1.5099272

\section{INTRODUCTION}

Microfluidic technology is promising for manipulating bioparticles such as circulating tumor cells (CTC), bacteria, proteins, DNAs, and other macromolecules in order to achieve point-of-care diagnostics. ${ }^{1}$ The bioparticles are commonly immersed in the aqueous solution during the biomedical operations using lab-on-a-chip devices under which circumstance efficient pumping of biological fluids is quite essential. With the progress of microfabrication techniques for complicated small electrode configurations, an electrokinetic phenomenon has been used as a popular tool to pump the fluid because of its several advantages including precise control of flow pattern and nonmechanical damage to microfluidic chips. ${ }^{2}$ In general, the most commonly used electrokinetic micropumps include the DC electroosmotic pump, the AC electroosmotic (ACEO) pump, and the AC electrothermal (ACET) pump, and they are applied in several different applications according to their distinct underlying driving 
mechanisms. An electric double layer (EDL) forms when the charged microchannel surface is in contact with an electrolyte solution. When a tangential electric field is applied to the microfluidic device, the ions in the EDL move due to the Coulomb force so that the corresponding electroosmotic flow occurs. The electroosmotic flow could be induced by both DC and AC voltage signals, and they are popularly used as pumping mechanisms in microfluidic devices as investigated by several researchers during the past decade. ${ }^{3}$ However, when the electrical conductivity of aqueous solutions is high or the AC voltage frequency exceeds $100 \mathrm{kHz}$, the electroosmotic flow becomes negligible due to the seriously compressed EDL. Hence, pumping the physiological solution of high electrical conductivity without predilution is difficult for electroosmotic micropumps.

Fortunately, ACET flow arises under the interaction of AC electric field and space charges induced by the variations of temperature-dependent electrical permittivity and conductivity of electrolyte solution caused through the Joule heating effect or external heat sources. ${ }^{4}$ Compared with electroosmotic flow, ACET flow is highly influential at physiological electrical conductivity and high AC voltage frequency making this biological fluid pumping phenomenon significant for liquid biopsy using lab-on-a-chip devices. Several research studies were carried out during recent years in order to optimize the efficiency of the ACET micropump as well as control its Joule heating effect. Wu et al. investigated the ACET pumping mechanism of biofluids with two different electrode configurations including a pair of coplanar electrodes with unequal width and $\mathrm{T}$ array electrodes. ${ }^{5}$ They presented that higher pumping efficiency could be achieved by using $\mathrm{T}$ array electrodes. In order to generate a fast ACET flow of conductive fluids with low temperature rise, Du et al. designed an enhanced ACET micropump using microgrooved electrodes instead of the coplanar ones, ${ }^{6}$ and an optimization methodology was further developed and applied to the patterned microgrooved electrodes. ${ }^{7}$ The results indicated that the optimum microgrooved electrode configuration generates a much faster ACET flow rate than the planar electrode configuration. Hong et al. systematically investigated the ACET pumping efficiency in terms of effects of electrode size, gap and length ratios, electrical conductivity of electrolyte solution, and magnitude and frequency of AC voltage signal. ${ }^{8}$ They concluded that the ACET flow is frequency-independent, and it becomes significant even in an ACEO micropump when the electrolyte solution conductivity and $\mathrm{AC}$ voltage magnitude increase. In addition, Hong et al. further developed a fully coupled numerical model for the ACET micropump, and they found that the variations of thermophysical properties of electrolyte solution should be considered to improve the modeling accuracy when the Joule heating induced temperature rise is high. ${ }^{9}$ As temperature gradient is the most important factor for inducing ACET flow, Williams et al. enhanced the ACET pumping rate with thin film resistive heaters, and they found that the thin film resistive heaters are more efficient than Joule heating for generating large temperature gradients to induce the ACET flow. ${ }^{10,11}$ Salari et al. applied multiple electrode arrays instead of a single electrode pair to enhance the ACET pumping flow rate. ${ }^{12}$ The results showed that the number of side electrode arrays and the actuation patterns greatly influence the ACET micropump performance. Besides the use of a single-phase AC voltage signal, Zhang et al. proposed an ACET micropump with two-phase AC voltage, ${ }^{13}$ and the numerical modeling demonstrated that the pumping flow rate is improved by up to $50 \%$ compared with the single-phase ACET micropump using certain designed parameters.

Based on the aforementioned fundamental investigation of the ACET flow phenomenon, the ACET micropump is successfully applied to distinguished biomedical applications including active fluid mixing ${ }^{14-16}$ and bioparticle manipulations using lab-on-a-chip devices. ${ }^{17}$ Specifically, for physiological solution of high electrical conductivity, the ACET phenomenon could be used to continuously drive the liquid sample with highly precise electric control. On the other hand, the electrohydrodynamic (EHD) force induced by the ACET flow could be combined with the dielectrophoresis (DEP) force to efficiently manipulate the motion of bioparticles for biomedical detections. Gao et al. reported a hybrid electrokinetic technique for label-free manipulation of pathogenic bacteria in urine and buffy depending on the combined short-range electrophoresis, dielectrophoresis, and long-range ACET flow. ${ }^{17}$ They found that the pathogenic bacteria could be concentrated for over 3 orders of magnitude using hybrid electrokinetics. Lang et al. designed a circulatory ACET micropump with 30 pairs of asymmetric electrodes, and the human embryonic kidney cells and human colon carcinoma cells are successfully circulated by $72 \mathrm{~h}$ for cell culture. ${ }^{18}$ Kale et al. discovered that the electrothermal flow vortices are capable to locally enrich the submicrometer particles near the insulating tips of the ratchet microchannel. ${ }^{19}$ Sato et al. numerically investigated the particle-fluid flow under AC electrokinetics, ${ }^{20}$ and the flow mechanism and dominant region of DEP and ACET phenomena are clarified and validated by the experiments. Sun et al. proposed a simplified multifunctional traffic control approach to realize continuous particle trapping, switching, and sorting with a combination of ACET flow and DEP force. ${ }^{21}$ Besides, our group investigated the long-range cell transport and suspension in a microfluidic chamber under the combined influences of negative dielectrophoresis and EHD force caused by ACET flow. We concluded that increasing the ratio between dielectrophoretic force and EHD force is the key factor for achieving stable cell suspension and patterning. ${ }^{22}$ In addition, we also designed an ACET micropump with castellated electrodes which eliminates the ACET flow vortex so that the bioparticles could be efficiently delivered in the microchannel filled with physiological conductivity biofluids. $^{23}$

However, the aforementioned research studies mainly focus on the ACET driving mechanisms of Newtonian physiological fluids. An efficient pumping technique of whole blood flow in lab-on-a-chip devices is indispensable for point-of-care diagnostic of several serious diseases such as bacterial detection in bloodstream infections (BSI) or capture of circulating tumor cells (CTC) for cancer inspection using microfluidic technologies. ${ }^{24,25}$ Different from the electrolyte solutions or urine, the non-Newtonian rheological behavior and AC frequency-dependent dielectric property of blood make its pumping mechanism intrinsically different from the Newtonian fluid. Recently, our group investigated the pumping mechanism of non-Newtonian blood flow under the AC electrothermal effect, and the results showed that the shear-thinning characteristic and excellent dielectric property of blood makes it highly appropriate for ACET pumping. ${ }^{26}$ However, a two-dimensional (2D) numerical approach is used in this work so that the electrode configuration design at different microfluidic channel surfaces is 
limited. Furthermore, as the shear stress of blood flow is dominant near the microfluidic channel surfaces, the shear-thinning behavior of ACET blood flow is overlooked with 2D simulation by neglecting the front and back boundary effects. Hence, in purpose of understanding the detailed physical mechanism of ACET driven blood flow in real lab-on-a-chip devices and optimizing their functional performances, a numerical modeling from a three dimensional (3D) perspective is necessary.

In this paper, the $3 \mathrm{D}$ lattice Boltzmann method (LBM) for electric field, temperature field, and non-Newtonian blood flow is developed and validated. Due to its mesoscopic kinetic nature, ${ }^{27,28}$ LBM is powerful for simulating different phenomena in microfluidics. ${ }^{29}$ With its characteristic of locally calculating the shear rate at each node using the nonequilibrium part of distribution functions, the rheological behavior of non-Newtonian fluid flow could be efficiently modeled by LBM. ${ }^{30}$ Among different non-Newtonian flow models, the Carreau-Yasuda model is appropriate for simulating whole blood flow due to its robust stability. ${ }^{31}$ Furthermore, with the development of graphics processor units (GPU), high performance computing has been achieved for LBM using GPU to investigate different fluid flows and heat transfer problems. ${ }^{32-35}$ Therefore, the Quadro GV 100 GPU is used in this work to accelerate the computational speed for studying ACET blood flow. The ACET pumping mechanism of non-Newtonian blood flow is investigated in detail in terms of the $\mathrm{AC}$ electrode configuration, $\mathrm{AC}$ voltage magnitude, and $\mathrm{AC}$ voltage frequency with consideration of the Joule heating effect on blood cell integrity. Besides, the rheological effect of blood on its ACET driven efficiency is discussed by comparing with ACET Newtonian flow using scaling law analysis. The remainder of the paper is organized as follows. In Sec. II, the theory of ACET shear-thinning blood flow and its Carreau-Yasuda model are presented. Then, the details about optimizing the 3D ACET blood micropump performance and future research perspective are discussed in Sec. III, and a conclusion is drawn in Sec. IV.

\section{THEORY}

The non-Newtonian ACET driven blood flow in lab-on-a-chip devices is a complicated process including multiple physical fields such as electric field, temperature field, and non-Newtonian fluid flow. The classical model derived by Ramos et al. is applied in the current work to simulate and optimize the performance of the ACET blood micropump. ${ }^{36}$ As the electrical conductivity of blood is high, the corresponding electrical double layer is extremely thin and the bulk region is electrically neutral. Under this situation, the electric potential $V$ is governed by Laplace's equation as ${ }^{37}$

$$
\nabla^{2} V=0
$$

The electric field $\boldsymbol{E}_{r m s}$ is defined by the negative gradient of electrical potential given as

$$
\boldsymbol{E}_{r m s}=-\nabla V
$$

The Joule heating $J H$ serving as the heat source of temperature gradient induces the variations of blood electrical conductivity and permittivity for generating ACET flow, and it is defined as

$$
J H=\sigma\left(\boldsymbol{E}_{r m s} \cdot \boldsymbol{E}_{r m s}\right),
$$

where $\sigma$ is the electrical conductivity of blood. Due to the small length scale of the microfluidic channel and its internal small ACET flow velocity, the Peclet number of heat transfer in the micropump is low which indicates the negligible convection effect. $^{38}$ Besides, the Joule heating generated by the electrical current could be treated as a steady heat source because of the high AC voltage frequency. Due to the above reasons, the temperature $T$ in the ACET blood micropump could be modeled by solving the steady state conduction heat transfer equation with source term as

$$
k \nabla^{2} T+\sigma\left(\boldsymbol{E}_{r m s} \cdot \boldsymbol{E}_{r m s}\right)=0,
$$

where $k$ is the thermal conductivity of blood. In addition, as the whole blood is incompressible fluid, the non-Newtonian blood flow in microfluidics is governed by the following continuity equation and Navier-Stokes equations:

$$
\begin{gathered}
\nabla \cdot \boldsymbol{u}=0, \\
\rho(\boldsymbol{u} \cdot \nabla \boldsymbol{u})=-\nabla p+\mu \nabla^{2} \boldsymbol{u}+\boldsymbol{F}_{\boldsymbol{e}}+\rho_{r} \beta_{T}\left(T-T_{r}\right) \boldsymbol{g},
\end{gathered}
$$

where $\rho$ is the density; $\boldsymbol{u}$ is the velocity vector of blood flow; $p$ is the pressure; $F_{e}$ is the AC electrothermal forces generated through the temperature gradient induced variation of blood dielectric properties; $\boldsymbol{g}$ is the gravitational acceleration; $\rho_{r}$ is the density at reference temperature $T_{r} ; \beta_{T}$ is the blood thermal expansion coefficient; $\mu$ is the dynamic viscosity, and it could be computed through the Carreau-Yasuda model in order to express the rheological behavior of non-Newtonian blood flow as ${ }^{31}$

$$
\mu(\dot{\gamma})=\mu_{\infty}+\left(\mu_{0}-\mu_{\infty}\right)\left[1+(\lambda \dot{\gamma})^{a}\right]^{(n-1) / a},
$$

where $\mu_{0}=0.022 \mathrm{Pas}$ and $\mu_{\infty}=0.0022 \mathrm{Pas}$ are the dynamic viscosities; $\lambda=0.11 \mathrm{~s}, a=0.644$, and $n=0.392$ are the empirical parameters; the shear rate $\dot{\gamma}$ is computed by the following equation:

$$
\dot{\gamma}=2 \sqrt{D_{l l}} \text {. }
$$

$D_{l l}$ is the second invariant of the strain rate tensor given as

$$
D_{l l}=\sum_{i, j=1}^{3} S_{i j} S_{i j}
$$

where $S_{i j}$ is the strain rate tensor defined by

$$
S_{i j}=\frac{1}{2}\left(\nabla_{j} u_{i}+\nabla_{i} u_{j}\right)
$$

The perturbation method is applied to approximately calculate the temperature induced variation of blood electrical permittivity $\varepsilon$ and 
conductivity $\sigma$ using a linear function of temperature $T$,

$$
\begin{gathered}
\delta_{\varepsilon}=\frac{1}{\varepsilon} \frac{d \varepsilon}{d T}, \quad \delta_{\sigma}=\frac{1}{\sigma} \frac{d \sigma}{d T}, \quad \varepsilon=\varepsilon_{r}\left[1+\delta_{\varepsilon}\left(T-T_{r}\right)\right], \\
\sigma=\sigma_{r}\left[1+\delta_{\sigma}\left(T-T_{r}\right)\right],
\end{gathered}
$$

where $\varepsilon_{r}$ and $\sigma_{r}$ are the reference permittivity and conductivity at reference temperature $T_{r}$. For the electrolyte solutions or urine, the ACET fluid velocity shows a weak relationship with AC voltage frequency as pointed by Lu et al. ${ }^{39}$ However, the dielectric properties of whole blood are highly frequency-dependent so that the ACET

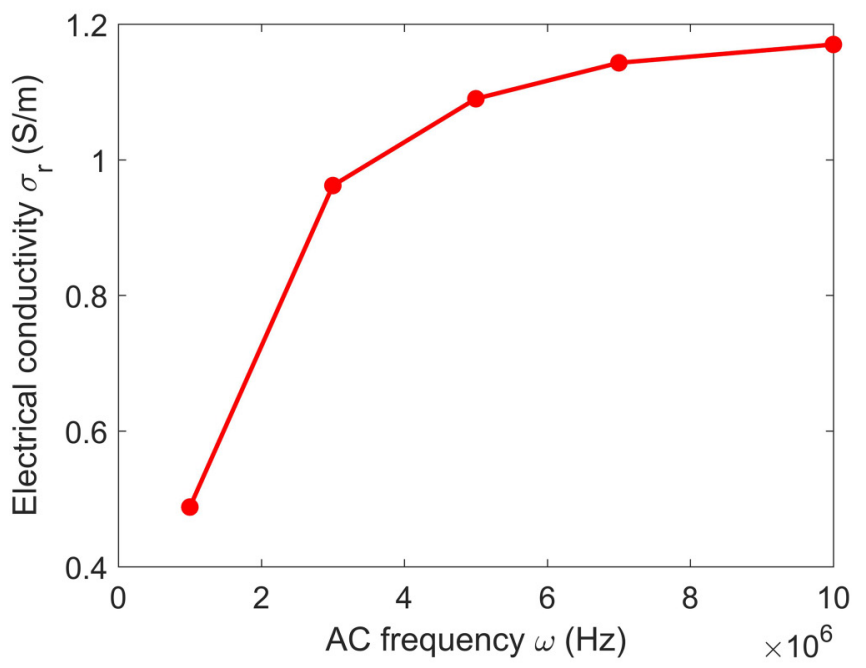

(a)

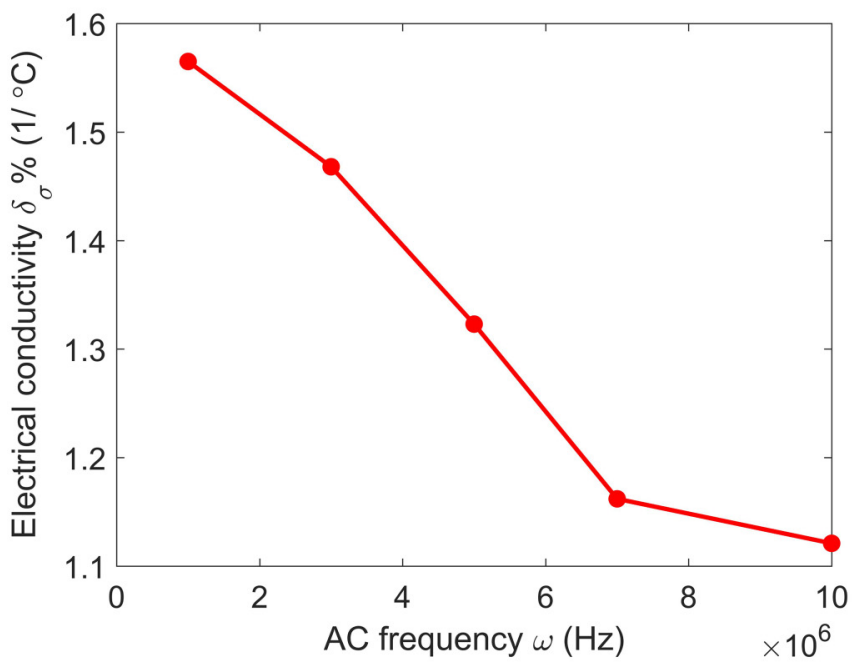

(c) driving mechanism of blood flow is intrinsically more complicated and attractive. The AC frequency-dependent relationships of blood dielectric properties and their variation rates with respect to temperature are displayed in Fig. 1. ${ }^{40,41}$ Besides, as the AC voltage with high frequency is applied to the microfluidic system so that the time average electrothermal forces are used in the current modeling as ${ }^{37}$

$$
\begin{aligned}
\boldsymbol{F}_{e}= & \frac{1}{2 \alpha}\left(\frac{\varepsilon_{r} \delta_{\sigma}(1-\alpha)}{\omega^{2} \tau^{2}+1}\left(\nabla T \cdot \boldsymbol{E}_{r m s}\right)\right) \boldsymbol{E}_{r m s} \\
& -\frac{1}{4 \alpha} \varepsilon_{r} \delta_{\sigma} \nabla T\left|\boldsymbol{E}_{r m s}\right|^{2},
\end{aligned}
$$

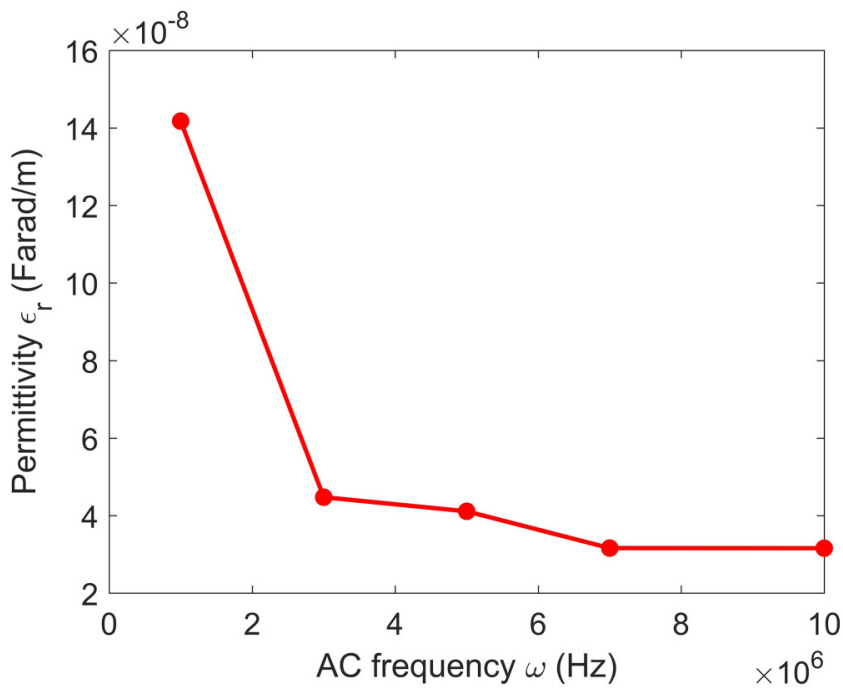

(b)

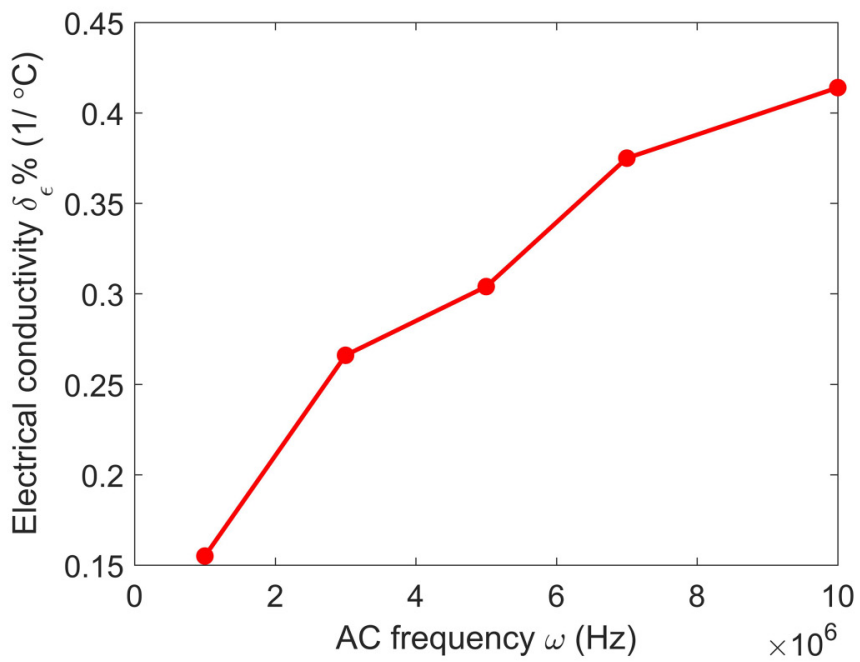

(d)

FIG. 1. Dielectric properties of blood in terms of AC voltage frequency: (a) electrical conductivity $\sigma$, (b) electrical permittivity $\varepsilon$, (c) electrical conductivity variation rate vs temperature $\delta_{\sigma}$, (d) electrical permittivity variation rate vs temperature $\delta_{\varepsilon}$ 
where $\tau=\frac{\varepsilon_{r}}{\sigma_{r}}$ is the charge relaxation time; the parameter $\alpha$ is defined as the ratio of $\frac{\delta_{\sigma}}{\delta_{\varepsilon}}$, and $\omega$ is the frequency of AC voltage signal. In Eq. (12), the first term of the right-hand side is the Coulomb force while the second term is the dielectric force. In this paper, the governing equations of ACET blood flow are solved by the lattice Boltzmann method (LBM) through matching the dimensionless governing parameters. The nondimensionalization of governing equations is presented in the Appendix as Eqs. (A1)-(A9). The details about LBM are discussed in the Appendix as Eqs. (A10)-(A25).

\section{RESULTS AND DISCUSSIONS}

As the ACET blood micropump is periodic in each electrode pair region, a unit of ACET blood micropump channel with a single electrode pair group of different configurations is studied in this paper. The schematic diagrams are displayed in Fig. 2, and the microfluidic system studied is $260 \mu \mathrm{m}$ in length with a cross section of $100 \times 100 \mu \mathrm{m}^{2}$. As shown in Fig. 2, the micropumps of Case A, Case B, and Case C use two electrodes, four electrodes, and eight electrodes, respectively. The electrode width $L_{w}$ and the electrode gap distance $L_{g}$ are set at $20 \mu \mathrm{m}$ in this paper except the investigations for their influences on ACET blood micropump performance. To make a fair comparison for the ACET blood micropump performance, the total electrode areas of Case A, Case B, and Case C are the same under which circumstance the electric energy consumptions are fixed. Besides, the blood micropump of Case D is generated by extending the electrode length $L_{e}$ to $100 \mu \mathrm{m}$ from Case C so that the ring electrodes are formed. The $\mathrm{AC}$ voltage signal with a phase difference of $180^{\circ}$ is applied on the left electrode and the right electrode. To simulate the electric potential distribution, the Dirichlet boundary conditions with electric potential magnitudes of

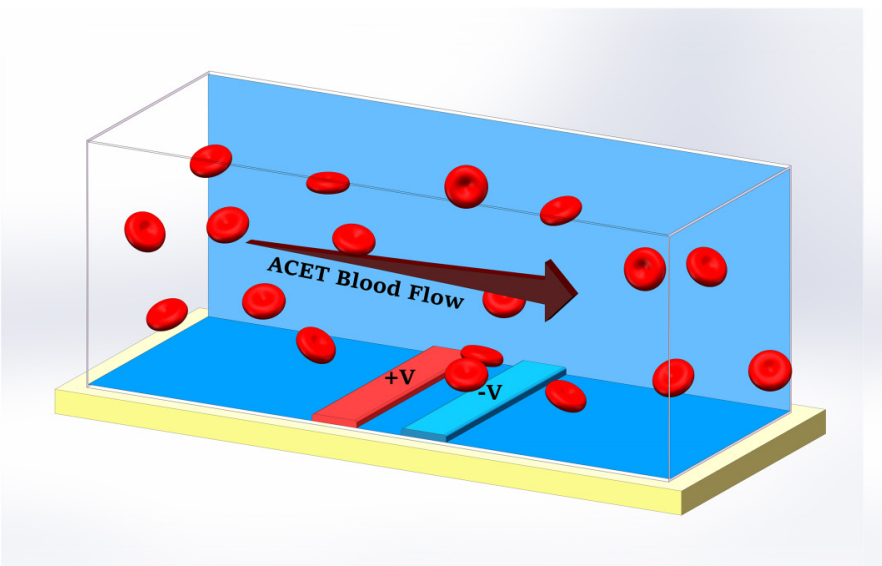

(a)

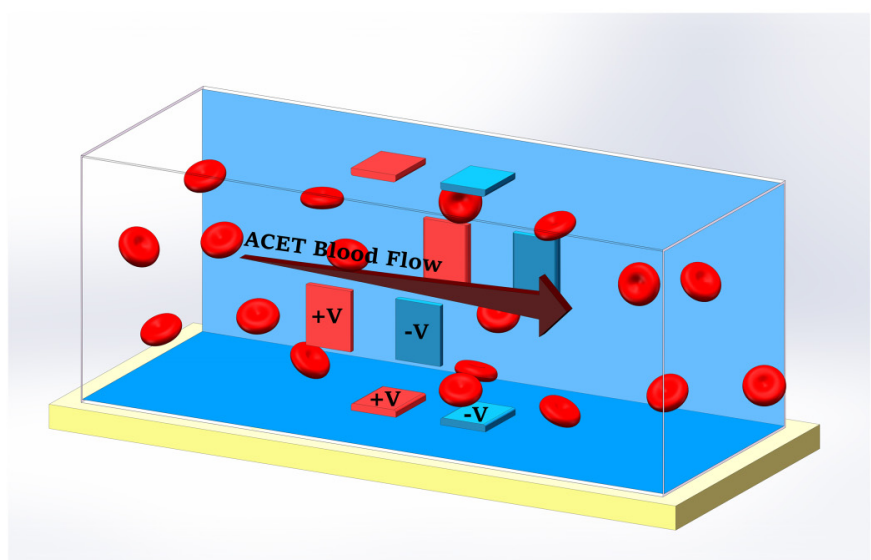

(c)

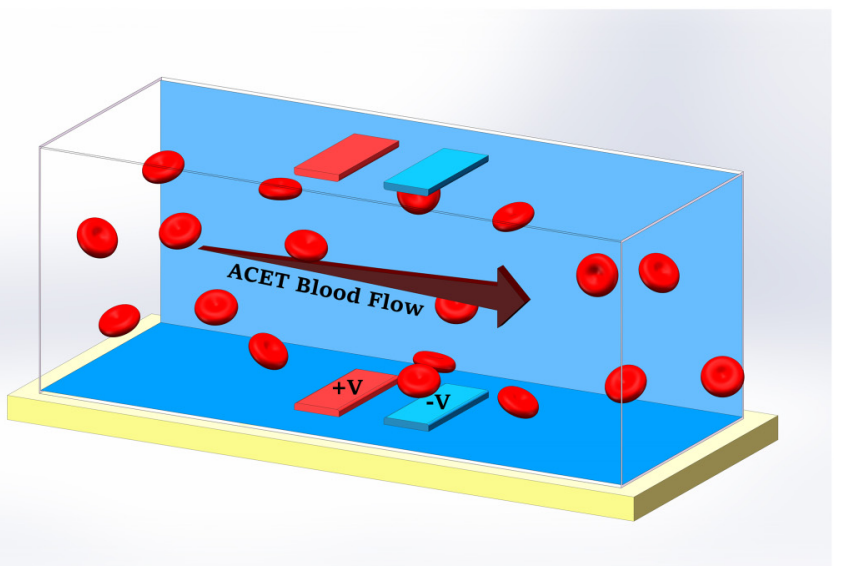

(b)

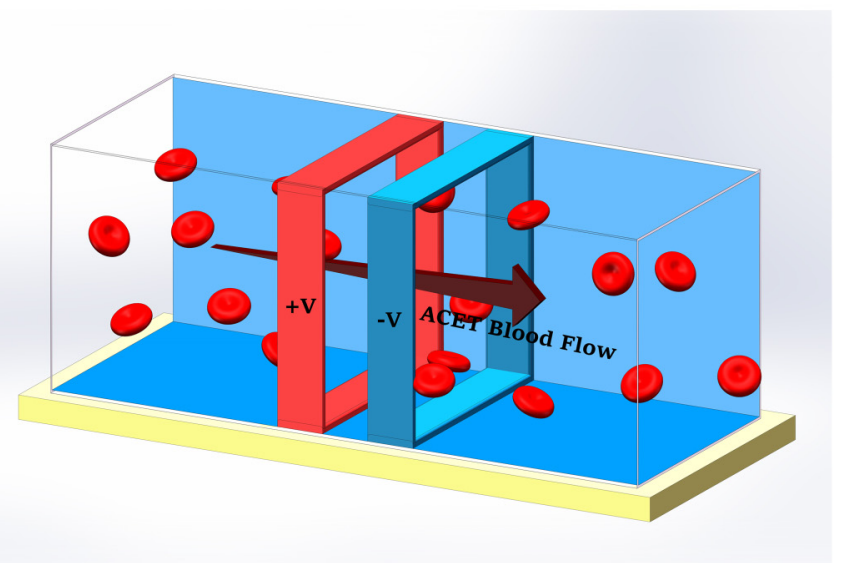

(d)

FIG. 2. Schematic diagram of ACET blood micropump unit: (a) Case A: two electrode pump, (b) Case B: four electrode pump, (c) Case C: eight electrode pump, (d) Case D: ring electrode pump. The electrode areas of Cases A, B, and C are the same, while Case D is designed from Case C by simultaneously extending the length of all electrodes until the ring electrodes are formed. 
$+V_{c}$ and $-V_{c}$ are applied on the electrodes while the other microchannel surfaces are electrically insulated. In addition, as the temperature gradient between electrodes is the most significant factor for inducing ACET flow as discussed in the references, ${ }^{10,11,26}$ the left electrode (red color in Fig. 2) is thermally insulated while the right electrode (blue color in Fig. 2) is set at the room temperature of $T_{r}=25^{\circ} \mathrm{C}$ because of the high thermal conductivities of common electrode materials. The adiabatic conditions are applied to the rest microchannel surfaces. For the non-Newtonian blood flow, the nonslip and nonpenetration conditions are applied on the lateral surfaces of microfluidic devices. Besides, as a unit of ACET blood micropump is investigated, the periodic conditions are applied for electric potential, temperature, and blood flow at the inlet and outlet of the microfluidic channel. The boundary conditions for electric potential, temperature, and blood flow used in the current modeling are summarized in Table III of Appendix. Besides, the values of physical parameters for ACET blood micropump are also displayed in Table IV of Appendix. Then, the ACET non-Newtonian blood micropump is investigated and optimized with respect to different $\mathrm{AC}$ electrode configurations, $\mathrm{AC}$ voltage magnitudes, AC signal frequencies, AC electrode lengths and widths, AC electrode gaps, and microfluidic channel length per electrode pair using the computational grid number of $312 \times$ $120 \times 120$ after grid independence check.

\section{A. ACET blood micropump with different electrode configurations}

The non-Newtonian blood micropumps of Case A, Case B, and Case $\mathrm{C}$ in Fig. 2 are studied in detail in this section to optimize the design of electrode configurations with an AC voltage magnitude of $V_{c}=2 \mathrm{~V}$ and a frequency of $\omega=10^{6} \mathrm{~Hz}$. In order to analyze the pumping efficiency of ACET blood flow, the average blood flow velocity $u_{\text {ave }}$ throughout the cross section of the microfluidic channel is defined as

$$
u_{\text {ave }}=\frac{1}{A} \int_{A} u d A
$$

where $u$ is the blood flow velocity distribution inside the cross section of microchannel and $A$ is the cross section area of microfluidic device. In Fig. 3, the performance of blood micropump Case A is displayed in terms of its electric potential [Fig. 3(a)], temperature field [Fig. 3(b)], and $u$ velocity profiles at a microchannel centerline of $x=130 \mu \mathrm{m}$ and an inlet of $x=0 \mu \mathrm{m}$ [Figs. 3(c) and $3(\mathrm{~d})]$. The electrical potential $V$ and its corresponding electric field $\boldsymbol{E}_{r m s}$ are dominant in the electrode region on the bottom surface, and they significantly decay to zero in the region away from the electrode pair. In addition, the temperature $T$ varies smoothly in most location of the microfluidic channel except the region between two electrodes due to the high thermal conductive right electrode and the thermally insulated left electrode. According to the expression of Eq. (12), the ACET forces are generated by the interaction between the temperature gradient induced variation of blood dielectric property and the electric field so that they are dominant in the electrode gap region on the microfluidic channel bottom. Hence, as shown in Fig. 3(c), the $u$ velocity at the center of the electrode pair $(x=130 \mu \mathrm{m})$ has its maximum value near the bottom surface $(z=0 \mu \mathrm{m})$, and it seriously decreases with respect to the $z$ coordinate which induces a large blood flow shear rate in this specific region. The average blood velocity $u_{\text {ave }}$ for micropump Case A is $1295 \mu \mathrm{m} / \mathrm{s}$. As a comparison, the electric potential, temperature field, and $u$ velocity profiles of micropump Case B with two electrode pairs on top and bottom surfaces are presented in Fig. 4. Similarly, the AC electric field and temperature gradient achieve their dominant values between electrodes on top and bottom microchannel surfaces which generate the maximum corresponding ACET forces. Under this situation, as displayed in Fig. 4(c), the $u$ velocity profile at the microfluidic channel centerline $(x=130 \mu \mathrm{m})$ has two peaks near the top and bottom electrode pair regions, respectively, and the velocity magnitude decays dramatically from the electrode regions to the microchannel center inducing a large blood flow shear rate. Through integration of the velocity distribution inside cross section at the microchannel inlet $(x=0 \mu \mathrm{m})$, the average blood velocity $u_{\text {ave }}$ of micropump Case B is $1500 \mu \mathrm{m} / \mathrm{s}$. Furthermore, the performance of blood micropump Case $\mathrm{C}$ using eight electrodes is presented in detail in Fig. 5. As shown in Fig. 5(c), the maximum ACET blood flow velocity occurs near each electrode pair because of the dominant ACET forces in this specific electrode gap region, and the average blood flow velocity $u_{\text {ave }}$ is $1684 \mu \mathrm{m} / \mathrm{s}$. By comparing the performances of micropump Case $\mathrm{A}$, Case $\mathrm{B}$, and Case $\mathrm{C}$ at a same parametric condition, the average blood flow velocity $u_{\text {ave }}$ increases from $1295 \mu \mathrm{m} / \mathrm{s}$ of Case A to $1684 \mu \mathrm{m} / \mathrm{s}$ of Case C with a fixed total electrode area. It means that the micropump Case $\mathrm{C}$ with eight shorter electrodes has higher pumping efficiency than micropump Case A with two longer electrodes. As previously discussed, a large blood flow shear rate could be induced around ACET force dominant electrode gap regions. With the increasing number of electrode pairs, the average ACET blood flow shear rate becomes larger in the microfluidic channel. As a result, the average blood viscosity of micropump Case C is less than that of Case A and Case B because of the blood shear-thinning characteristic. Hence, when the electric energy consumption amount is fixed, using a microfluidic device with more pairs of smaller electrodes is more efficient than that with a less number of larger electrodes for ACET pumping of non-Newtonian blood flow. Based on the above discussions, the blood micropump of Case $\mathrm{C}$ is chosen in the following section to investigate the effects of $\mathrm{AC}$ voltage magnitude, $\mathrm{AC}$ signal frequency, $\mathrm{AC}$ electrode length and width, AC electrode gaps, and microchannel length per electrode pair on its ACET pumping efficiency.

\section{B. Influences of AC voltage magnitude and frequency}

As the ACET blood flow is generated by the interaction between electric field and Joule heating induced temperature gradients, the AC voltage magnitude $V_{c}$ is the most significant factor which affects the pumping efficiency of ACET microfluidic devices. In Fig. 6(a), the average flow velocity $u_{\text {ave }}$ of ACET blood micropump with eight electrodes (Case C) is plotted in terms of different AC voltage magnitude $V_{c}$ at frequency $\omega=10^{6} \mathrm{~Hz}$. The average blood velocity $u_{\text {ave }}$ in the pumping direction is $1.35 \mu \mathrm{m} / \mathrm{s}$, $54.68 \mu \mathrm{m} / \mathrm{s}, 444.8 \mu \mathrm{m} / \mathrm{s}, 1684 \mu \mathrm{m} / \mathrm{s}$, and $4452 \mu \mathrm{m} / \mathrm{s}$, respectively, when the AC voltage magnitude $V_{c}$ varies from $0.5 \mathrm{~V}$ to $2.5 \mathrm{~V}$ with 


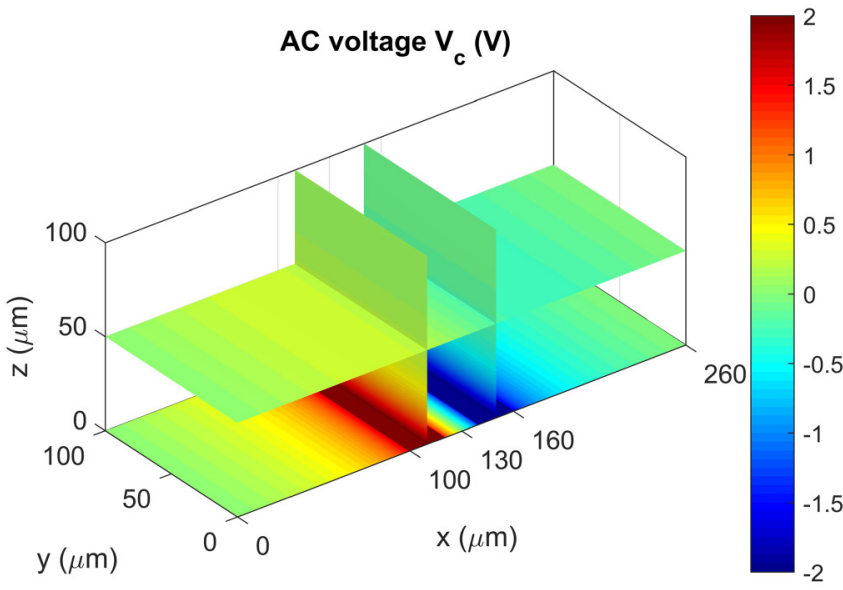

(a)

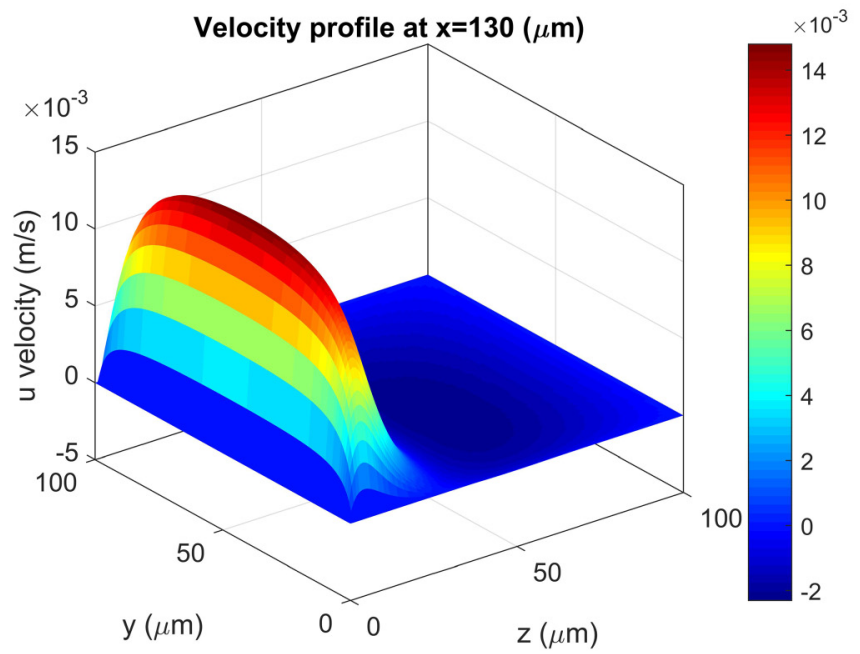

(c)

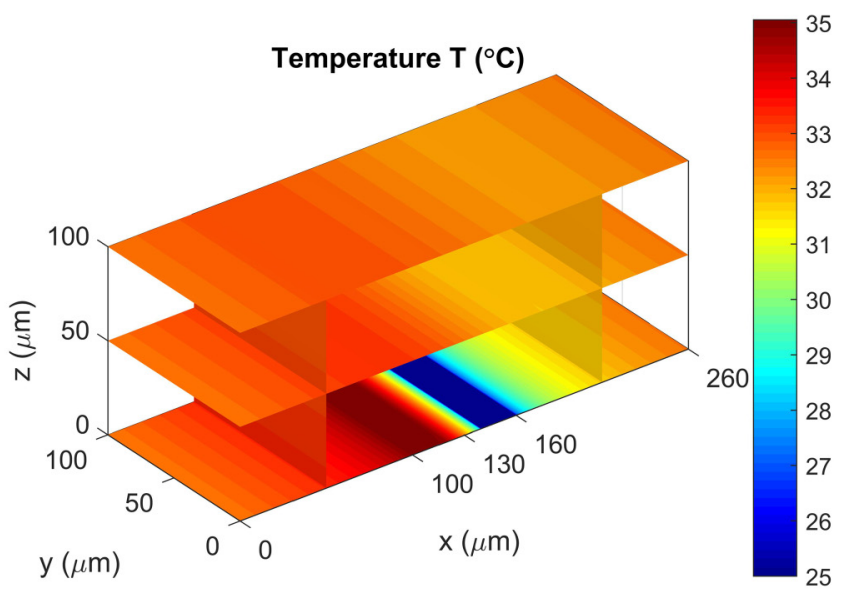

(b)

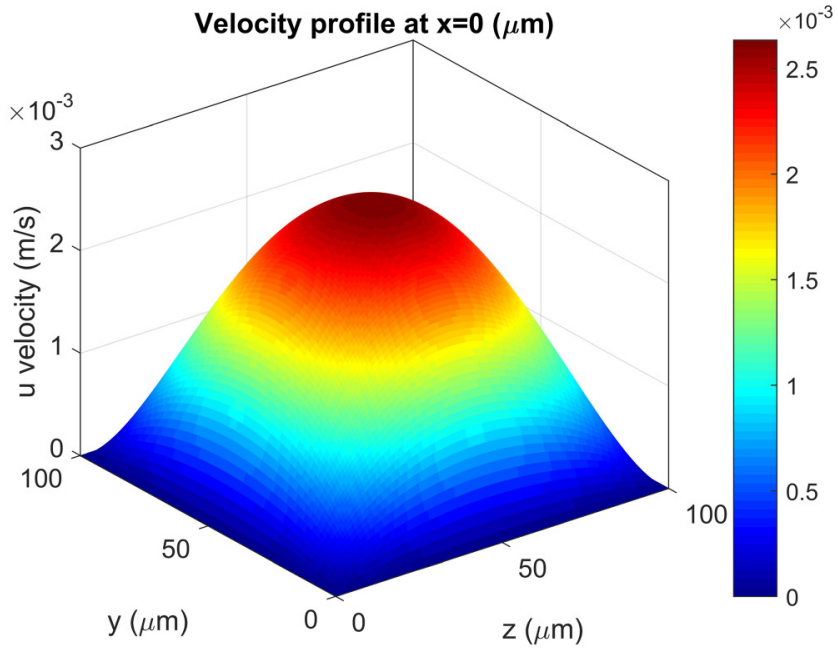

(d)

FIG. 3. ACET blood micropump with two electrodes of $L_{e}=100 \mu \mathrm{m}$ : (a) AC electric potential, (b) temperature, (c) $u$ velocity (pumping direction) profile at the centerline of $x=130 \mu \mathrm{m}$, (d) $u$ velocity (pumping direction) profile at the inlet of $x=0 \mu \mathrm{m}$.

an interval of $0.5 \mathrm{~V}$. It is demonstrated that varying the AC voltage magnitude $V_{c}$ is highly sensitive for controlling the ACET blood flow pumping rate. To clarify the rheological behavior of non-Newtonian ACET blood flow, a scaling law analysis is carried out to compute the ACET flow rate for Newtonian fluid. From the nondimensional analysis as presented in Eqs. $A(1)-A(9)$, the characteristic velocity of ACET blood flow is $U_{c}=\frac{\varepsilon_{r} \delta_{\sigma} \Delta T V_{c}^{2}}{\mu_{\infty} L_{c}}$ with Joule heating induced temperature rise of $\Delta T=\frac{\sigma_{r} V_{c}^{2}}{k}$. Due to this reason, the average ACET blood flow velocity $u_{\text {ave }}$ is proportional to $V_{c}^{4}$. Under this situation, by using the ACET blood flow average velocity $u_{\text {ave }}=1.35 \mu \mathrm{m} / \mathrm{s}$ with an AC voltage magnitude of $V_{c}=0.5 \mathrm{~V}$ as a reference, the Newtonian ACET flow average velocity $u_{\text {ave }}$ for
AC voltage magnitude $V_{c}$ from $1.0 \mathrm{~V}$ to $2.5 \mathrm{~V}$ is calculated and presented in Fig. 6(a). At the AC voltage magnitude of $V_{c}=2.5 \mathrm{~V}$, the Newtonian ACET average flow velocity $u_{\text {ave }}$ is $843.8 \mu \mathrm{m} / \mathrm{s}$ which is increased by 625 times compared with the case of $V_{c}=0.5 \mathrm{~V}$. However, for the non-Newtonian blood flow, the average flow velocity $u_{\text {ave }}$ is increased from $1.35 \mu \mathrm{m} / \mathrm{s}$ to $4452 \mu \mathrm{m} / \mathrm{s}$ by 3300 times when the AC voltage of $V_{c}=2.5 \mathrm{~V}$ is used instead of $V_{c}=0.5 \mathrm{~V}$. According to this result, it is obvious that the shearthinning characteristic of non-Newtonian blood makes its ACET flow rate increase more rapidly compared with Newtonian ACET flow due to the shear rate induced decrement of blood viscosity. Besides the pumping efficiency, the temperature rise $\Delta T$ caused by Joule heating should be seriously controlled in designing the ACET 


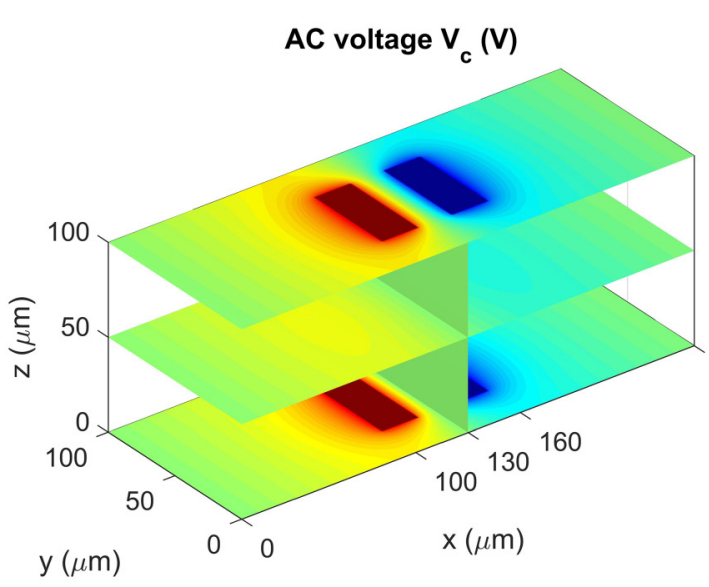

(a)

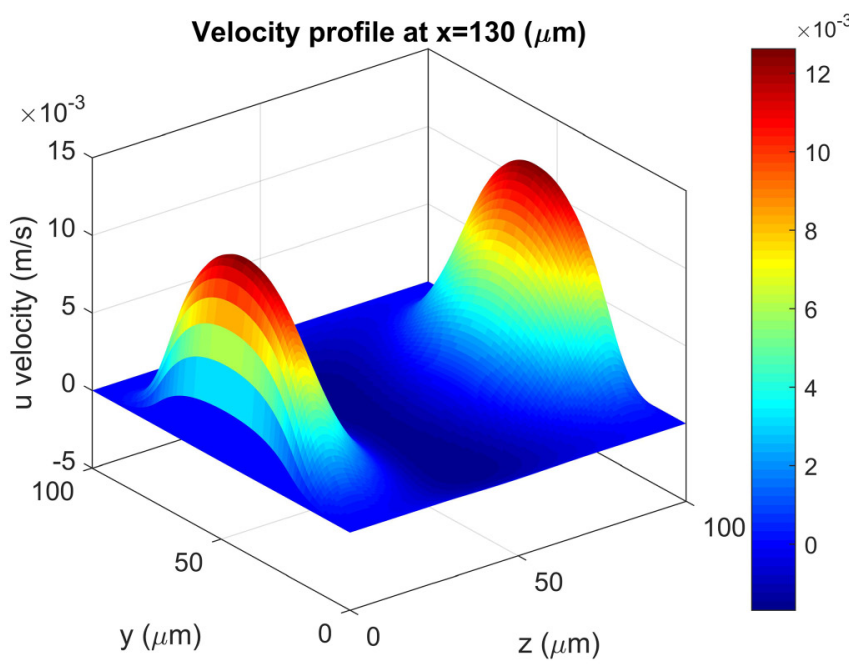

(c)

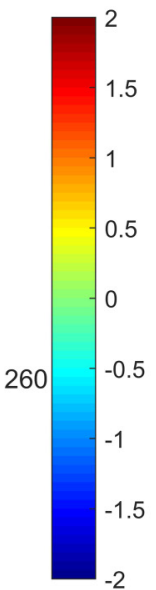

FIG. 4. ACET blood micropump with four electrodes of $L_{e}=50 \mu \mathrm{m}$ : (a) AC electric potential, (b) temperature, (c) $u$ velocity (pumping direction) profile at the centerline of $x=130 \mu \mathrm{m}$, (d) $u$ velocity (pumping direction) profile at the inlet of $x=0 \mu \mathrm{m}$.

micropump, especially for high electrical conductivity blood in order to avoid the blood cell damage in a high temperature environment. As displayed in Fig. 6(b), the maximum temperature $T_{\max }$ of blood micropump increases with respect to the increment of AC voltage magnitude $V_{c}$. For the ACET blood micropump with eight electrodes and an $\mathrm{AC}$ voltage signal of $V_{c}=2.5 \mathrm{~V}$ and $\omega=10^{6} \mathrm{~Hz}$, its maximum temperature $T_{\max }$ is $35.05^{\circ} \mathrm{C}$ which is safe for keeping blood cell integrity. In addition, as aforementioned, the average blood flow velocity $u_{\text {ave }}$ for this micropump case is $4452 \mu \mathrm{m} / \mathrm{s}$ which is more than sufficient for microfluidic operations. Hence, it could be concluded that the ACET phenomenon is highly effective for pumping blood flow because of its good dielectric property and non-Newtonian shear-thinning characteristic.

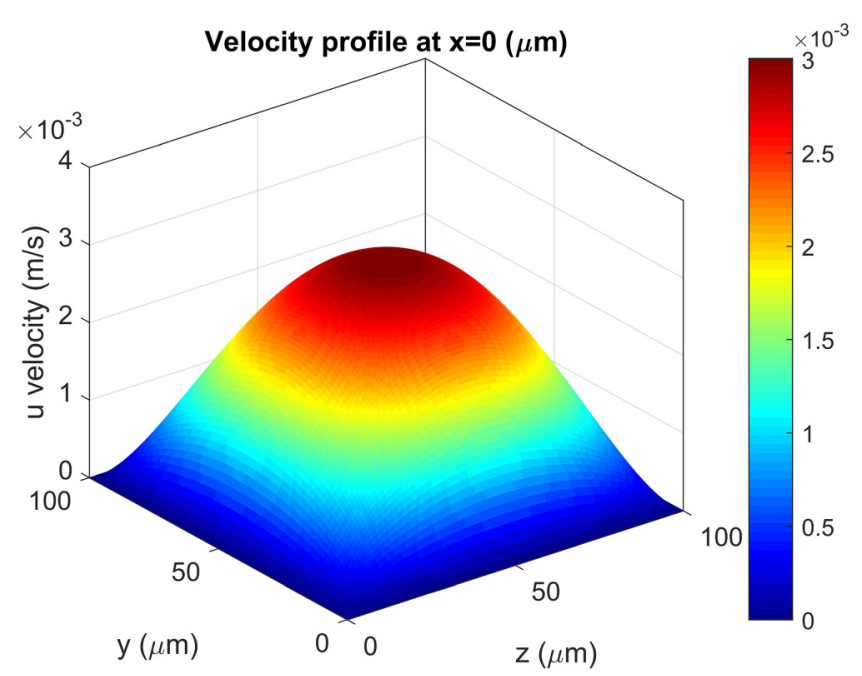

(d)

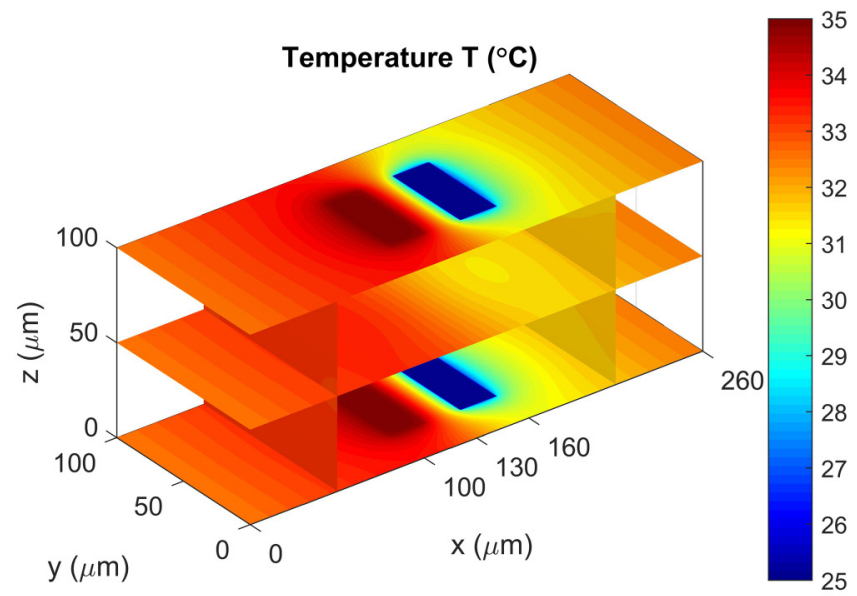

(b)

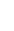




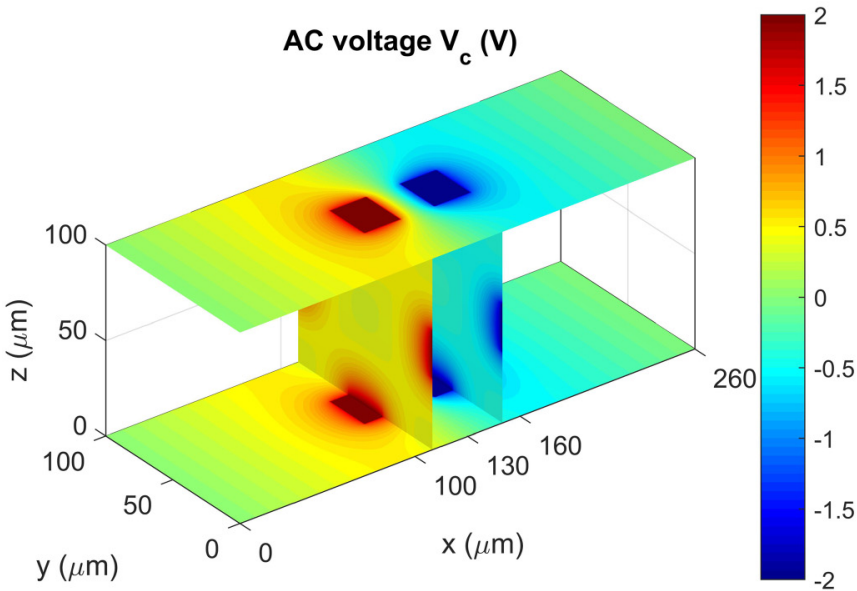

(a)

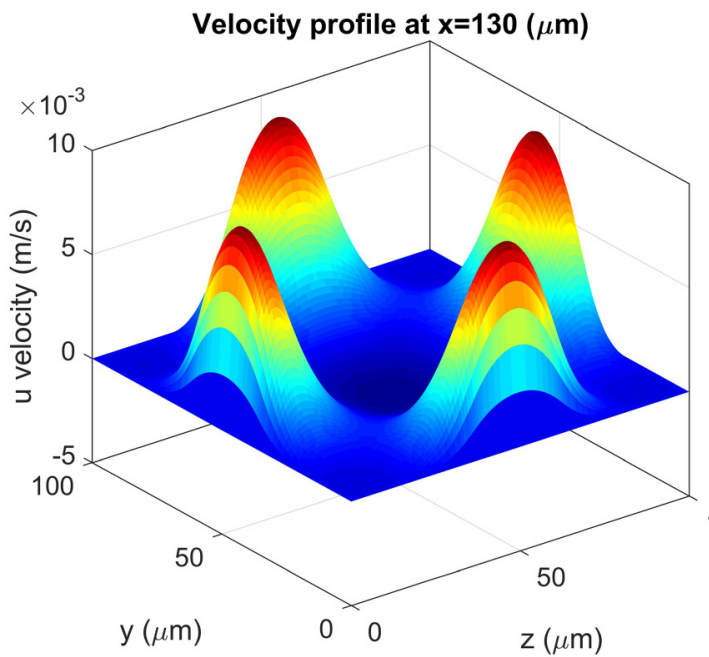

(c)

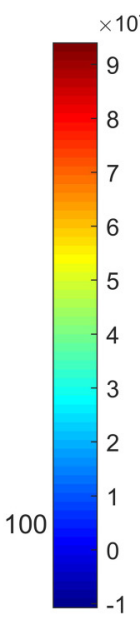

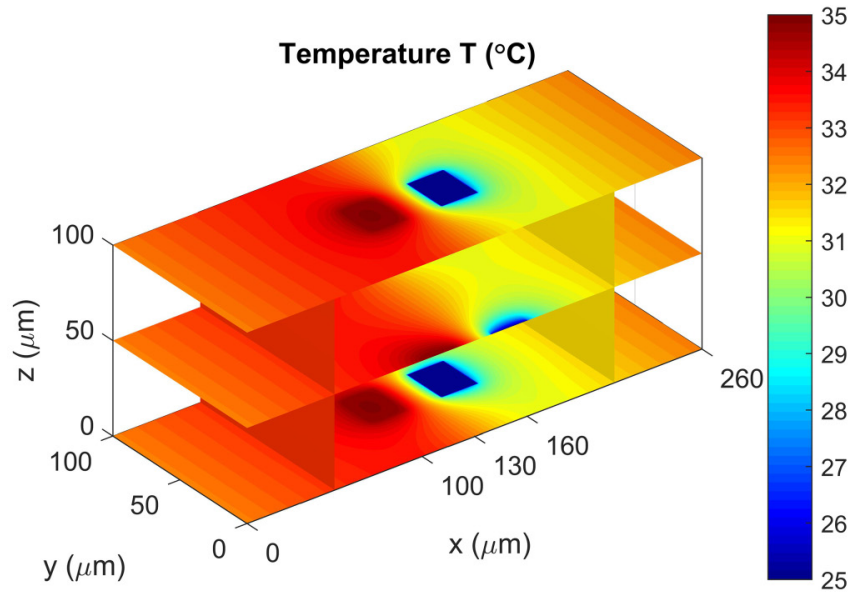

(b)

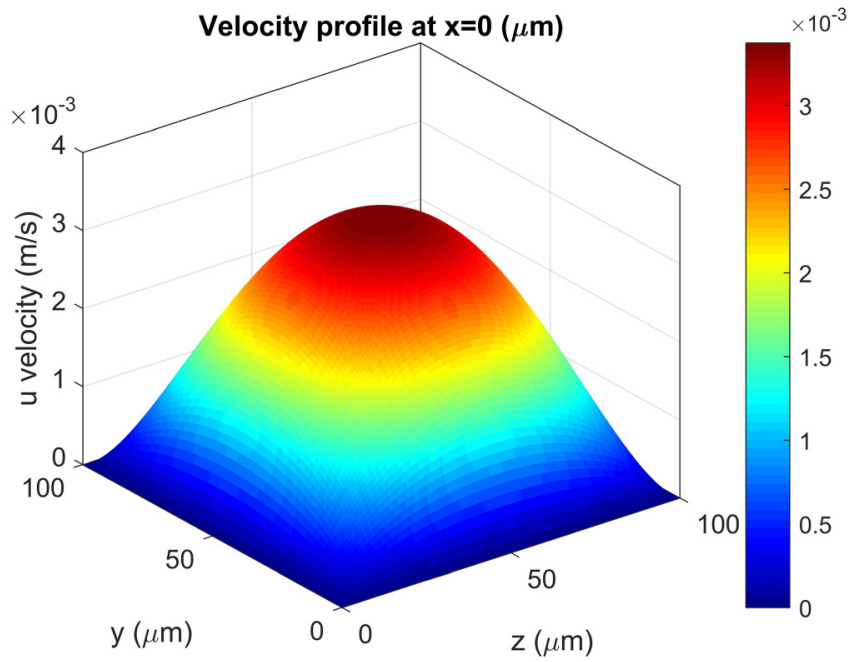

(d)

FIG. 5. ACET blood micropump with eight electrodes of $L_{e}=25 \mu \mathrm{m}$ : (a) AC electric potential, (b) temperature, (c) $u$ velocity (pumping direction) profile at the centerline of $x=130 \mu \mathrm{m}$, (d) $u$ velocity (pumping direction) profile at the inlet of $x=0 \mu \mathrm{m}$.

with $u_{\text {ave }}=1684 \mu \mathrm{m} / \mathrm{s}$ at $\omega=10^{6} \mathrm{~Hz}$ as a reference. It could be observed in Fig. 7 (a) that the average velocity $u_{\text {ave }}$ of non-Newtonian blood micropump decreases more rapidly than that of the ACET Newtonian micropump because of the shearthinning behavior of blood and its increased viscosity caused by the decreasing flow shear rate. Furthermore, the maximum temperature $T_{\max }$ for blood micropump with eight electrodes in terms of different AC voltage magnitude $V_{c}$ and frequency $\omega$ is displayed in Fig. 7 (b). The results indicate that the maximum temperature $T_{\max }$ becomes higher with the increment of AC signal frequency $\omega$ at a specific AC voltage magnitude $V_{c}$ due to the consolidated Joule heating effects caused by the enhanced blood electrical conductivity. Hence, the AC voltage signal with lower frequency $\omega$ is highly recommended to pump the ACET non-Newtonian blood flow in a microfluidic biosensor with higher flow rate and weaker Joule heating effects.

\section{Enhancement of ACET blood pumping with ring electrodes}

With the aforementioned discussions, the ACET micropump with eight electrodes (Case $\mathrm{C}$ ) using AC voltage with relatively low signal frequency $\omega$ is beneficial for driving the non-Newtonian blood flow in a microfluidic channel. In this section, the influence of AC electrode length on pumping efficiency of ACET blood micropump is investigated at an AC signal frequency of $\omega=10^{6} \mathrm{~Hz}$ in terms of 


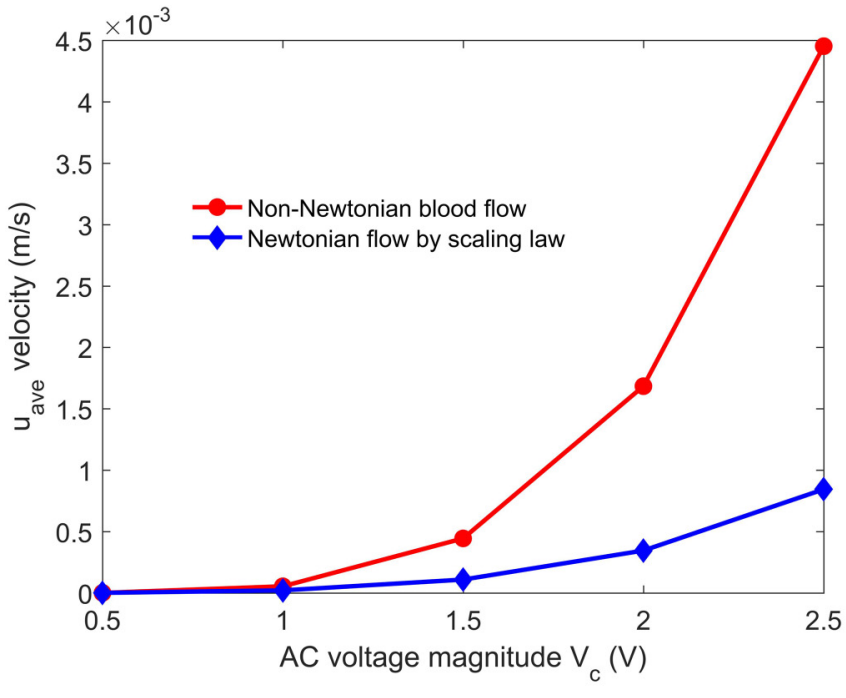

(a)

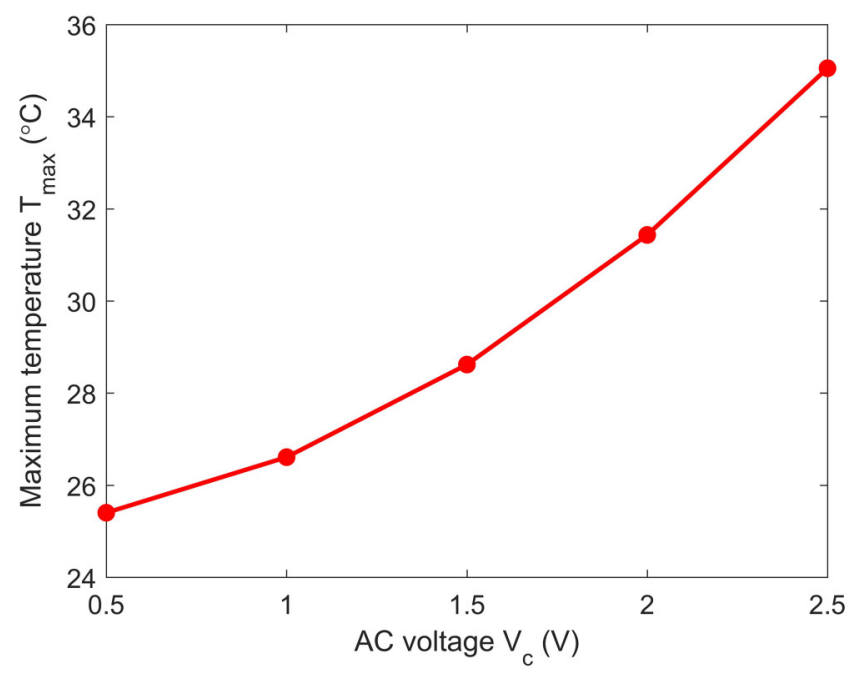

(b)

FIG. 6. (a) The average pumping direction velocity $U_{\text {ave }}$ and (b) maximum temperature $T_{\max }$ of ACET blood micropump with eight electrodes with respect to AC voltage magnitudes at $\omega=10^{6} \mathrm{~Hz}$.

different AC voltage magnitude $V_{c}$. When the lengths of eight AC electrodes (Case C) are simultaneously extended to $L_{e}=100 \mu \mathrm{m}$, the ring shape electrodes are formed for the ACET blood micropump (Case D) as shown in Fig. 2(d). In Fig. 8, the performance of ACET blood micropump with ring electrodes is displayed with respect to electric potential [Fig. 8(a)], temperature field [Fig. 8(b)], and $u$ velocity profiles at $x=130 \mu \mathrm{m}$ and $x=0 \mu \mathrm{m}$ [Figs. 8(c) and 8(d)]. The average blood flow velocity $u_{\text {ave }}$ for ACET blood micropump Case D is $7541 \mu \mathrm{m} / \mathrm{s}$ at $V_{c}=2 \mathrm{~V}$ and a frequency of $\omega=10^{6} \mathrm{~Hz}$ which is faster than that of Case A, Case B, and Case C. Hence, the

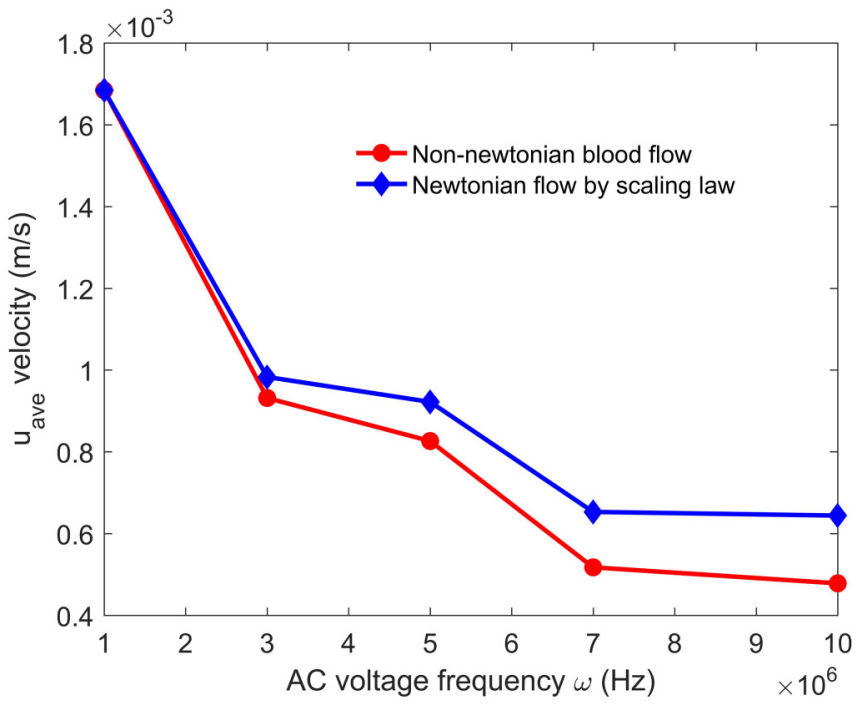

(a)

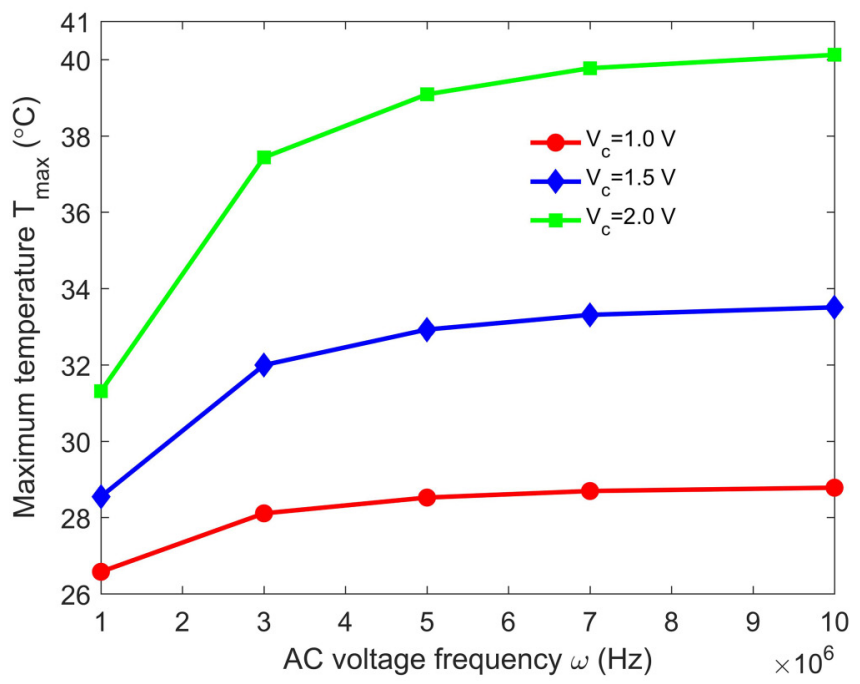

(b)

FIG. 7. (a) The average pumping direction velocity $u_{\text {ave }}$ at $V_{c}=2.0 \mathrm{~V}$ and (b) maximum temperature $T_{\max }$ of ACET blood micropump with eight electrodes with respect to $A C$ voltage frequencies. 


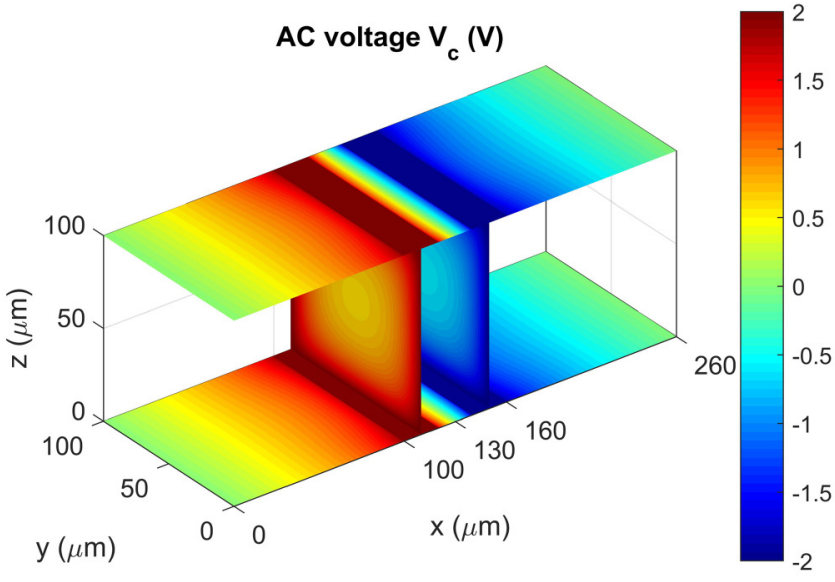

(a)

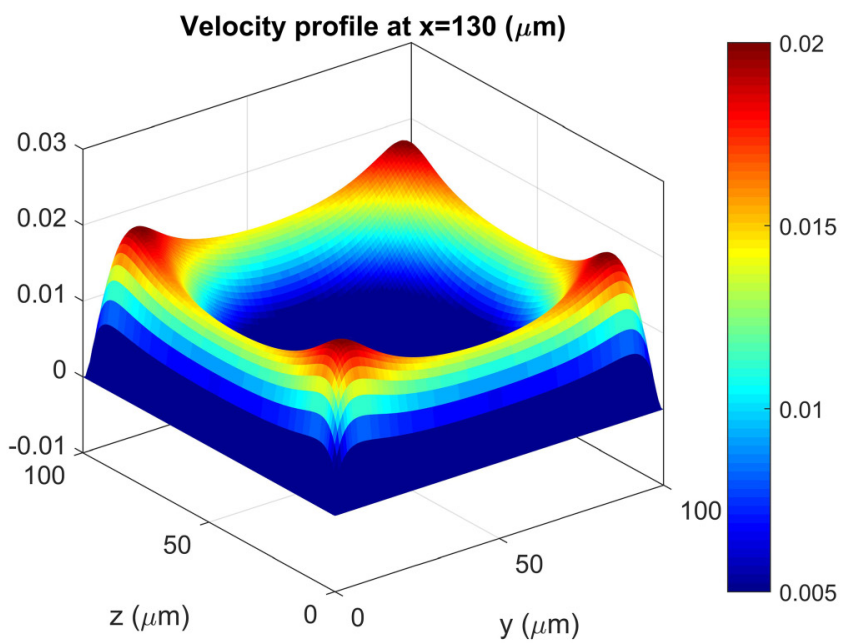

(c)

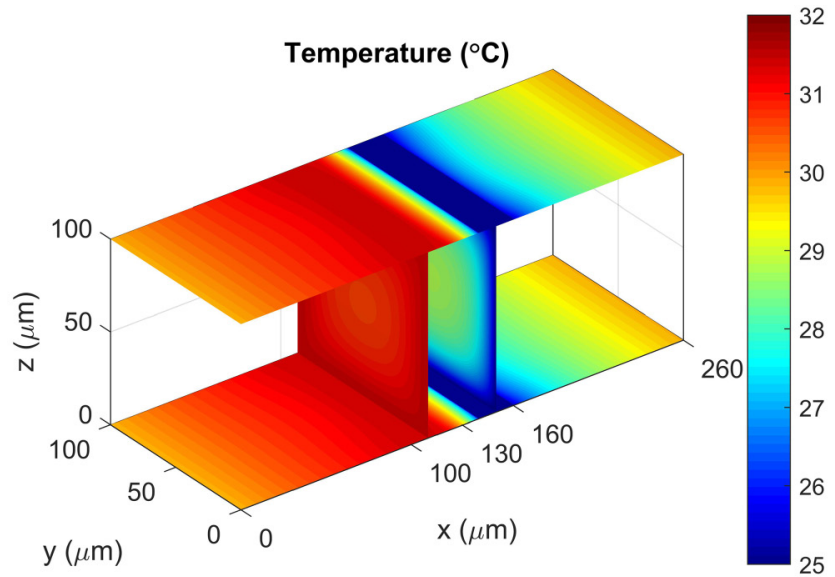

(b)

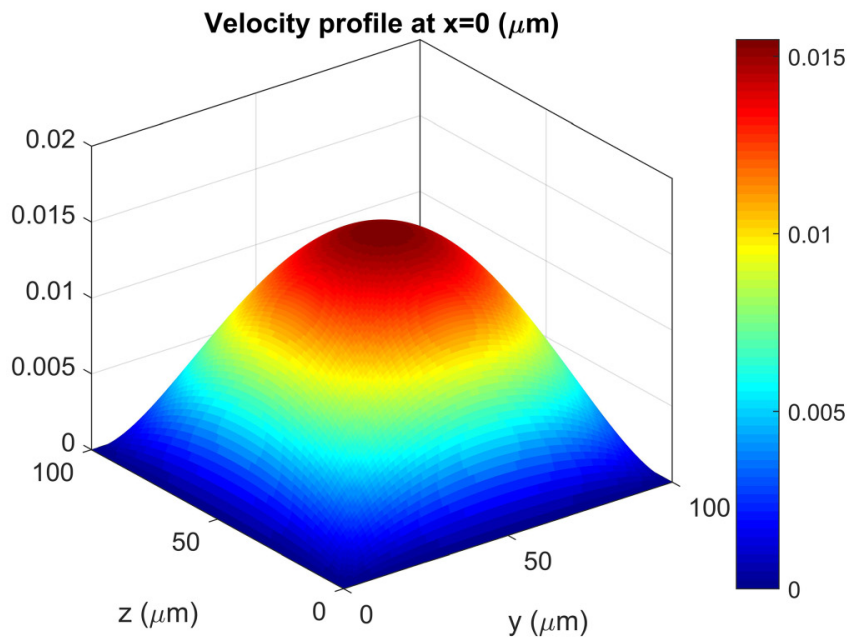

(d)

FIG. 8. ACET blood micropump with eight electrodes of length $L_{e}=100 \mu \mathrm{m}$ : (a) AC electric potential, (b) temperature, (c) $u$ velocity (pumping direction) profile at the centerline of $x=130 \mu \mathrm{m}$, (d) $u$ velocity (pumping direction) profile at the inlet of $x=0 \mu \mathrm{m}$.

ACET blood micropump with ring electrodes is desired for highly efficient pumping in lab-on-a-chip devices.

The average blood flow velocity $u_{\text {ave }}$ is plotted in Fig. 9(a) with respect to different AC voltage magnitude $V_{c}$ and AC electrode length $L_{e}$. The results indicate that the average blood velocity $u_{\text {ave }}$ is increased by $22.11,17.74$, and 15.89 times at $V_{c}=1.5 \mathrm{~V}$, $V_{c}=2.0 \mathrm{~V}$, and $V_{c}=2.5 \mathrm{~V}$, respectively, when the AC electrode length is increased from $L_{e}=10 \mu \mathrm{m}$ to $L_{e}=100 \mu \mathrm{m}$. It is interesting to note that the enhancement ratio of average ACET blood micropump velocity $u_{\text {ave }}$ actually decreases when the AC voltage magnitude $V_{c}$ becomes large. To explain this phenomenon, as displayed in Fig. 8(c), when the ring electrodes are used for the ACET blood micropump, the velocity profile in the cross section surface is symmetric, and its corresponding shear rate becomes less due to the decreased velocity gradient. According to this reason, when an AC electrode with larger area is used, there exists a tradeoff influence between the increasing ACET forces and the reduced blood shear-thinning caused viscosity decrement. As the effect of blood shear-thinning characteristic becomes more dominant at a relatively higher AC voltage magnitude $V_{c}$ as shown in Fig. 6(a), the increased $\mathrm{AC}$ electrode length plays a more significant role on the reduced shear rate rather than the increased ACET forces when AC voltage magnitude $V_{c}$ increases from $1.5 \mathrm{~V}$ to $2.5 \mathrm{~V}$. As a consequence, the increment ratio of average ACET blood velocity $u_{\text {ave }}$ by extending the AC electrode length decreases. However, it should be pointed out that using ring electrodes with $L_{e}=100 \mu \mathrm{m}$ still has the maximum pumping flow rate at a specific AC voltage magnitude $V_{c}$ as shown by Fig. 9(a). Furthermore, when the AC electrode 


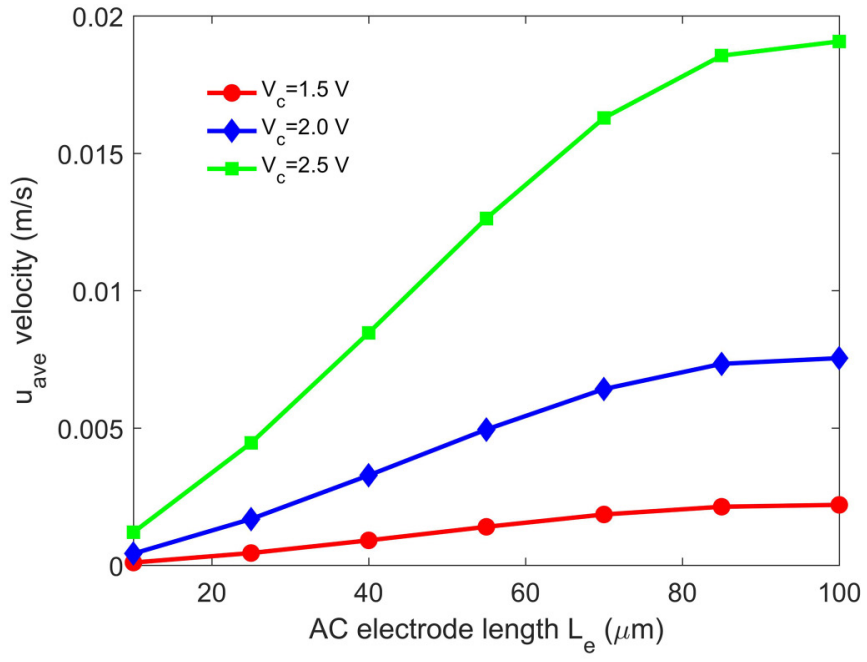

(a)

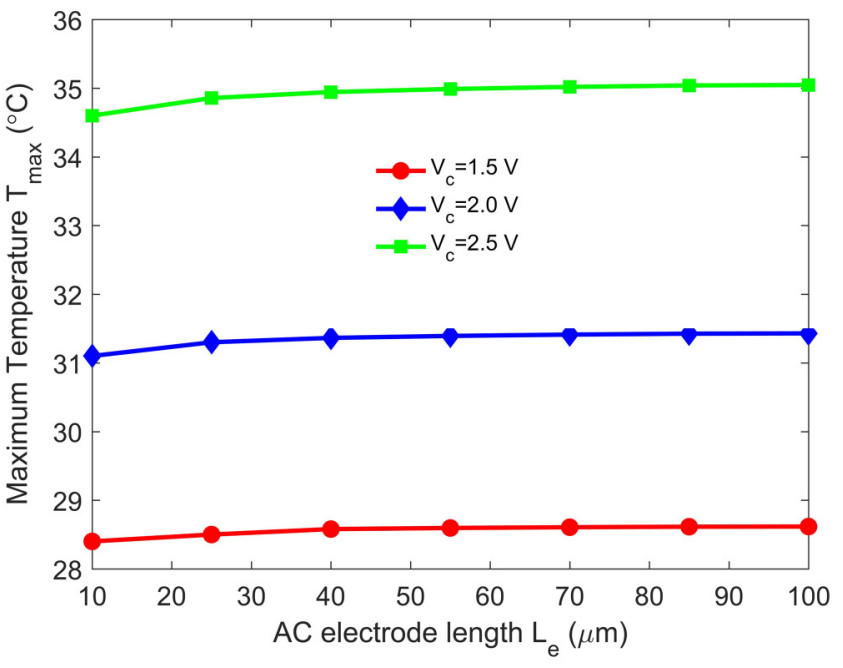

(b)

FIG. 9. (a) The average pumping direction velocity $u_{\text {ave }}$ and (b) maximum temperature $T_{\max }$ of ACET blood micropump with eight electrodes with respect to different electrode length $L_{e}$.

length is extended, the Joule heating effect is consolidated due to the enlarged electrode area so that the corresponding temperature rise $\Delta T$ should be carefully investigated. As presented in Fig. 9(b), the maximum temperature $T_{\max }$ inside the microfluidic device has a negligible rise of $\Delta T=0.22{ }^{\circ} \mathrm{C}, \Delta T=0.33^{\circ} \mathrm{C}$, and $\Delta T=0.45^{\circ} \mathrm{C}$ at $V_{c}=1.5 \mathrm{~V}, V_{c}=2.0 \mathrm{~V}$, and $V_{c}=2.5 \mathrm{~V}$, respectively, when the electrode length is increased from $L_{e}=10 \mu \mathrm{m}$ to

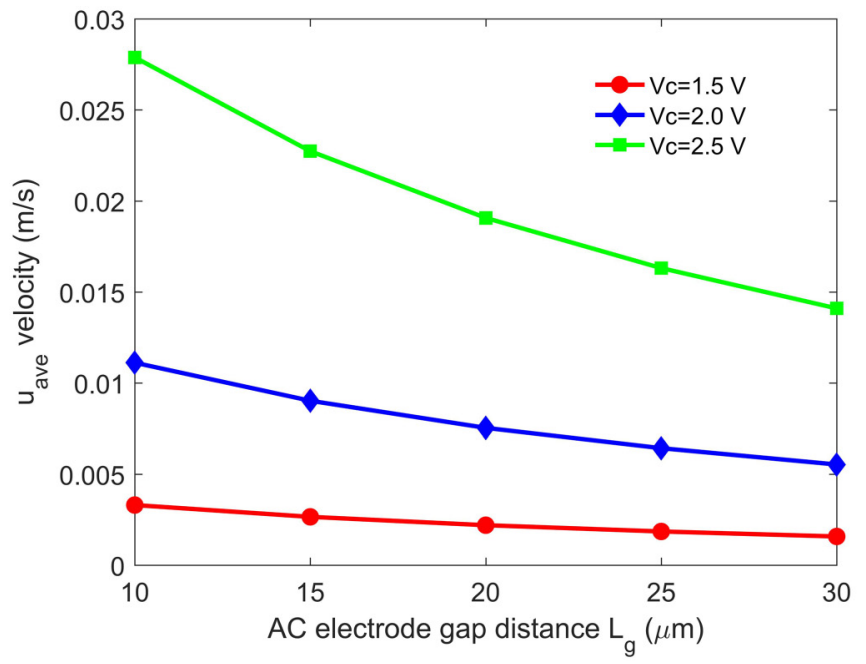

(a)
$L_{e}=100 \mu \mathrm{m}$. Although the Joule heating effect becomes large with the increasing AC electrode area, the heat transfer area between blood and the right electrode of high thermal conductivity is also enlarged. Therefore, more heat could be efficiently dissipated out of the microfluidic channel from the right electrode under which situation the maximum temperature $T_{\max }$ inside the micropump is almost unchanged. These observations demonstrate that the ACET

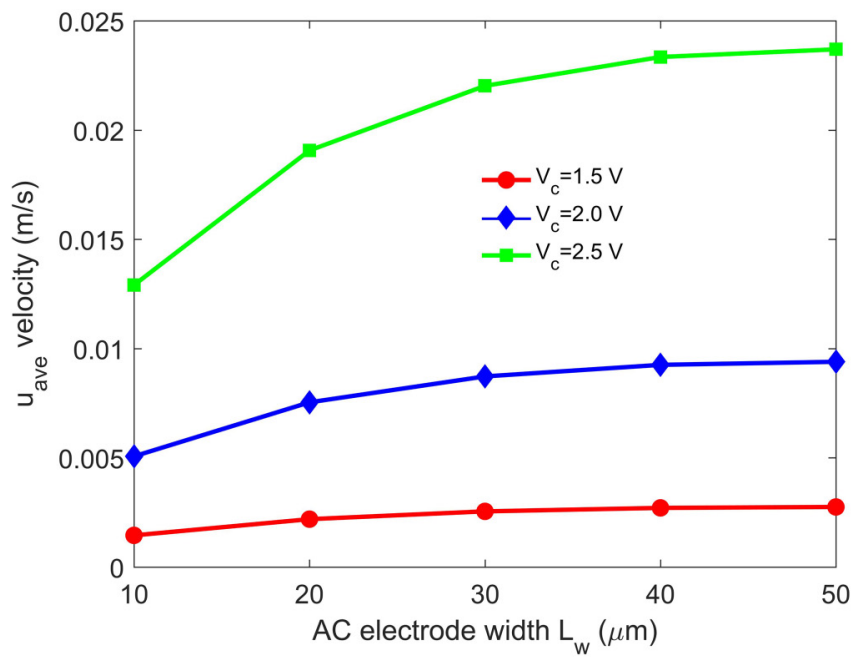

(b)

FIG. 10. (a) The average pumping direction velocity $u_{\text {ave }}$ with different electrode gap $L_{g}$ at $L_{e}=100 \mu \mathrm{m}$ and $L_{w}=20 \mu \mathrm{m}$. (b) The average pumping direction velocity $u_{\text {ave }}$ with different electrode width $L_{w}$ at $L_{e}=100 \mu \mathrm{m}$ and $L_{w}=20 \mu \mathrm{m}$. 
micropump with ring electrode is effective for pumping blood flow with acceptable Joule heating induced temperature rise.

Furthermore, the influence of electrode gap $L_{g}$ and electrode width $L_{w}$ on the pumping efficiency of ACET blood microdevice is investigated in order to further evaluate its performance. As shown in Fig. 10(a), the average ACET blood flow velocity $u_{\text {ave }}$ decreases with the increasing electrode gap $L_{g}$ because of the simultaneously weakened electric field $\boldsymbol{E}_{r m s}$ and temperature gradient $\nabla T$ for generating ACET forces. For instance, at the AC voltage of $V_{c}=2.5 \mathrm{~V}$, when the electrode gap distance increases from $L_{g}=10 \mu \mathrm{m}$ to $L_{g}=30 \mu \mathrm{m}$, the average ACET blood flow velocity $u_{\text {ave }}$ varies from $27883 \mu \mathrm{m} / \mathrm{s}$ to $14101 \mu \mathrm{m} / \mathrm{s}$ which is actually decreased by $49.4 \%$. Therefore, a relatively small electrode gap distance $L_{g}$ is preferred to enhance the ACET blood flow rate when the microfabrication accuracy is sufficient. However, the Joule heating effect could become larger with respect to the decreasing electrode gap $L_{g}$, especially when high AC voltage is applied so that the temperature rise $\Delta T$ needs to be seriously controlled for point-of-care diagnostic applications. On the other hand, the effect of AC electrode width on the average ACET blood velocity is studied vs AC voltage magnitude $V_{c}$ as presented in Fig. 10(b). In general, the average ACET blood velocity $u_{\text {ave }}$ increases in terms of the increasing AC electrode width. However, the enhancement rate of average ACET blood flow velocity $u_{\text {ave }}$ by enlarging the electrode width is limited. For example, at the AC voltage of $V_{c}=2.5 \mathrm{~V}$, the average ACET blood flow velocity $u_{\text {ave }}$ is increased by $6159 \mu \mathrm{m}$ when the AC eletrode width extends from $L_{w}=10 \mu \mathrm{m}$ to $L_{w}=20 \mu \mathrm{m}$. As a comparison, when the AC electrode width is increased from $L_{w}=40 \mu \mathrm{m}$ to $L_{w}=50 \mu \mathrm{m}$, the increment of average ACET blood flow velocity $u_{\text {ave }}$ is only $351 \mu \mathrm{m}$. Furthermore, the AC electrode with enlarged width consumes more electric energy and generates more Joule heat which is not beneficial for efficiently pumping the whole blood without damaging the cell blood and proteins. Due to this reason, the AC electrode width should be appropriately designed in purpose of pumping the blood flow with high efficiency. In addition, the average blood flow velocity $u_{\text {ave }}$ in the ACET micropump is summarized in Table I for clarity at different electrode length $L_{e}$, electrode gap $L_{g}$, and electrode width $L_{w}$ with respect to AC voltage magnitude $V_{c}$.

\section{Energy consumption analysis of ACET blood micropump}

As a periodic unit of ACET blood micropump is investigated in the above sections, it is indispensable to investigate the influence of microfluidic channel length per electrode pair $L_{p}$ on the pumping efficiency and carry out the corresponding energy consumption analysis. The average blood flow velocity $u_{\text {ave }}$ using ring electrodes with an $\mathrm{AC}$ signal frequency of $\omega=10^{6} \mathrm{~Hz}$ is presented in Fig. 11 in terms of different AC voltage magnitude $V_{c}$ and microfluidic channel length per electrode pair $L_{p}$. When the microfluidic channel length per electrode pair decreases from $L_{p}=300 \mu \mathrm{m}$ to $L_{p}=140 \mu \mathrm{m}$, it

TABLE I. ACET blood micropump average velocity $u_{\text {ave }}$ at different electrode length $L_{e}$, electrode gap $L_{g}$, and electrode width $L_{w}$ vs $A C$ voltage magnitude $V_{c}$.

\begin{tabular}{|c|c|c|c|}
\hline Voltage $V_{c}$ & $1.5 \mathrm{~V}$ & $2.0 \mathrm{~V}$ & $2.5 \mathrm{~V}$ \\
\hline $\begin{array}{l}\text { Electrode length } \\
L_{e}(\mu \mathrm{m}) \\
\end{array}$ & & $\begin{array}{l}L_{w}=20 \mu \mathrm{m} \\
L_{w}=20 \mu \mathrm{m}\end{array}$ & \\
\hline 10 & $u_{\text {ave }}=99.5 \mu \mathrm{m} / \mathrm{s}$ & $u_{\text {ave }}=425 \mu \mathrm{m} / \mathrm{s}$ & $u_{\text {ave }}=1200 \mu \mathrm{m} / \mathrm{s}$ \\
\hline 25 & $u_{\text {ave }}=445 \mu \mathrm{m} / \mathrm{s}$ & $u_{\text {ave }}=1684 \mu \mathrm{m} / \mathrm{s}$ & $u_{\text {ave }}=4452 \mu \mathrm{m} / \mathrm{s}$ \\
\hline 40 & $u_{\text {ave }}=907 \mu \mathrm{m} / \mathrm{s}$ & $u_{\text {ave }}=3274 \mu \mathrm{m} / \mathrm{s}$ & $u_{\text {ave }}=8462 \mu \mathrm{m} / \mathrm{s}$ \\
\hline 55 & $u_{\text {ave }}=1404 \mu \mathrm{m} / \mathrm{s}$ & $u_{\text {ave }}=4942 \mu \mathrm{m} / \mathrm{s}$ & $u_{\text {ave }}=12629 \mu \mathrm{m} / \mathrm{s}$ \\
\hline 70 & $u_{\text {ave }}=1851 \mu \mathrm{m} / \mathrm{s}$ & $u_{\text {ave }}=6415 \mu \mathrm{m} / \mathrm{s}$ & $u_{\text {ave }}=16283 \mu \mathrm{m} / \mathrm{s}$ \\
\hline 85 & $u_{\text {ave }}=2131 \mu \mathrm{m} / \mathrm{s}$ & $u_{\text {ave }}=7332 \mu \mathrm{m} / \mathrm{s}$ & $u_{\text {ave }}=18552 \mu \mathrm{m} / \mathrm{s}$ \\
\hline 100 & $u_{\text {ave }}=2195 \mu \mathrm{m} / \mathrm{s}$ & $u_{\text {ave }}=7541 \mu \mathrm{m} / \mathrm{s}$ & $u_{\text {ave }}=19068 \mu \mathrm{m} / \mathrm{s}$ \\
\hline Electrode gap & & $L_{e}=100 \mu \mathrm{m}$ & \\
\hline$L_{g}(\mu \mathrm{m})$ & & $L_{w}=20 \mu \mathrm{m}$ & \\
\hline 10 & $u_{\text {ave }}=3301 \mu \mathrm{m} / \mathrm{s}$ & $u_{\text {ave }}=11117 \mu \mathrm{m} / \mathrm{s}$ & $u_{\text {ave }}=27883 \mu \mathrm{m} / \mathrm{s}$ \\
\hline 15 & $u_{\text {ave }}=2655 \mu \mathrm{m} / \mathrm{s}$ & $u_{\text {ave }}=9029 \mu \mathrm{m} / \mathrm{s}$ & $u_{\text {ave }}=22734 \mu \mathrm{m} / \mathrm{s}$ \\
\hline 20 & $u_{\text {ave }}=2195 \mu \mathrm{m} / \mathrm{s}$ & $u_{\text {ave }}=7541 \mu \mathrm{m} / \mathrm{s}$ & $u_{\text {ave }}=19068 \mu \mathrm{m} / \mathrm{s}$ \\
\hline 25 & $u_{\text {ave }}=1851 \mu \mathrm{m} / \mathrm{s}$ & $u_{\text {ave }}=6423 \mu \mathrm{m} / \mathrm{s}$ & $u_{\text {ave }}=16313 \mu \mathrm{m} / \mathrm{s}$ \\
\hline 30 & $u_{\text {ave }}=1576 \mu \mathrm{m} / \mathrm{s}$ & $u_{\text {ave }}=5527 \mu \mathrm{m} / \mathrm{s}$ & $u_{\text {ave }}=14101 \mu \mathrm{m} / \mathrm{s}$ \\
\hline Electrode width & & $L_{e}=100 \mu \mathrm{m}$ & \\
\hline$\underline{L_{w}(\mu \mathrm{m})}$ & & $L_{g}=20 \mu \mathrm{m}$ & \\
\hline 10 & $u_{\text {ave }}=1454 \mu \mathrm{m} / \mathrm{s}$ & $u_{\text {ave }}=5071 \mu \mathrm{m} / \mathrm{s}$ & $u_{\text {ave }}=12909 \mu \mathrm{m} / \mathrm{s}$ \\
\hline 20 & $u_{\text {ave }}=2195 \mu \mathrm{m} / \mathrm{s}$ & $u_{\text {ave }}=7541 \mu \mathrm{m} / \mathrm{s}$ & $u_{\text {ave }}=19068 \mu \mathrm{m} / \mathrm{s}$ \\
\hline 30 & $u_{\text {ave }}=2552 \mu \mathrm{m} / \mathrm{s}$ & $u_{\text {ave }}=8727 \mu \mathrm{m} / \mathrm{s}$ & $u_{\text {ave }}=22024 \mu \mathrm{m} / \mathrm{s}$ \\
\hline 40 & $u_{\text {ave }}=2711 \mu \mathrm{m} / \mathrm{s}$ & $u_{\text {ave }}=9256 \mu \mathrm{m} / \mathrm{s}$ & $u_{\text {ave }}=23344 \mu \mathrm{m} / \mathrm{s}$ \\
\hline 50 & $u_{\text {ave }}=2753 \mu \mathrm{m} / \mathrm{s}$ & $u_{\text {ave }}=9397 \mu \mathrm{m} / \mathrm{s}$ & $u_{\text {ave }}=23695 \mu \mathrm{m} / \mathrm{s}$ \\
\hline
\end{tabular}




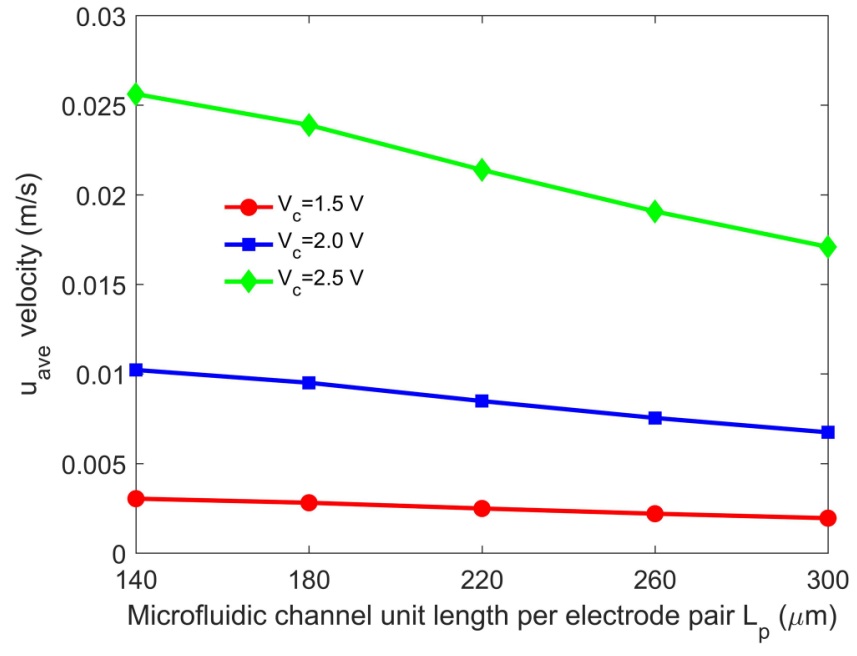

FIG. 11. The average pumping direction velocity $u_{\text {ave }}$ at an $\mathrm{AC}$ voltage signal of $\omega=10^{6} \mathrm{~Hz}$ and different voltage magnitudes with respect to microfluidic channel length per electrode pair $L_{p}$.

is indicated that the average blood flow velocity $u_{\text {ave }}$ increases from $1947 \mu \mathrm{m} / \mathrm{s}, \quad 6737 \mu \mathrm{m} / \mathrm{s}$, and $17090 \mu \mathrm{m} / \mathrm{s}$ to $3036 \mu \mathrm{m} / \mathrm{s}$, $10220 \mu \mathrm{m} / \mathrm{s}$, and $25620 \mu \mathrm{m} / \mathrm{s}$ at an AC voltage magnitude of $V_{c}=1.5 \mathrm{~V}, 2.0 \mathrm{~V}$, and $2.5 \mathrm{~V}$, respectively. Indeed, the average blood flow velocity $u_{\text {ave }}$ of micropump with $L_{p}=140 \mu \mathrm{m}$ is increased to $1.559,1.517$, and 1.499 times of that micropump with $L_{p}=300 \mu \mathrm{m}$ at different $\mathrm{AC}$ voltage magnitudes. The electrical energy consumption rate $P$ of ACET blood micropump could be defined as

$$
P=\frac{V_{c}^{2}}{R} \frac{L_{t}}{L_{p}},
$$

where $R$ is the electrical resistance of electrode which is a constant for specific ring electrode configurations and $L_{t}$ is the total length of microfluidic devices. According to Eq. (14), the electrical energy consumption rate $P$ of the total microfluidic system with $L_{p}=140 \mu \mathrm{m}$ is 2.143 times of that with $L_{p}=300 \mu \mathrm{m}$ at the same AC voltage magnitude. However, the corresponding ACET blood flow average velocity $u_{\text {ave }}$ is only increased to no more than 1.559 times for the aforementioned cases. On the other hand, the electrical energy consumption rate $P$ is proportional to $V_{c}^{2}$. When the electrical energy consumption rate $P$ is increased to 2.143 times, the corresponding AC voltage magnitude $V_{c}$ is actually increased by $\sqrt{2.143}$ times. As previously analyzed, the ACET Newtonian flow velocity is proportional to $V_{c}^{4}$, and the ACET blood flow has a higher velocity increment with increasing AC voltage magnitude than ACET Newtonian flow due to its shearthinning characteristic. When the AC voltage magnitude $V_{c}$ is actually increased to $\sqrt{2.143}$ times, the ACET blood flow velocity could be accelerated to more than 4.592 times. Hence, increasing the AC voltage magnitude $V_{c}$ is a more economical approach for enhancing the ACET blood flow rate than adding more electrode pairs in the microfluidic systems if the temperature rise $\Delta T$ caused by the Joule heating effect is acceptable for keeping blood cell integrity.

\section{Future research perspectives}

As the micro- and nanotechnologies have achieved tremendous progress during the past two decades, developing functional lab-on-a-chip devices to pump non-Newtonian blood flow or manipulate bioparticles is essential for point-of-care diagnostics including bacterial bloodstream infections (BSI) or rapid detection of circulating tumor cells (CTC). The current work numerically demonstrates the efficiency of the ACET phenomenon for pumping the blood flow in microfluidic devices due to the excellent blood dielectric property and its shear-thinning characteristic. However, experimental work is still indispensable in recent future to study the adhesion of blood cells and protein macromolecules on electrodes for fouling issue which may hinder the ACET blood flow pumping process. In addition, the Joule heating effect on the viability of bioparticles including blood cells, proteins, bacteria, or circulating tumor cells also needs further experimental calibration. Besides, compared with the electrode-based AC electrokinetics, the insulatorbased AC electrokinetics have several advantages such as metal-free fabrication and lesser sensitivity for electrode fouling. Due to this reason, the ACET blood flow could be induced by the nonuniform Joule heating effect generated with insulator obstacles inside the microfluidic channel, and the adhesion issue of blood cells and proteins on electrodes could be eliminated making the insulator-based ACET blood micropump more attractive for further investigation. Furthermore, based on the precisely controlled AC electrokinetic selfpumping instead of using the mechanical micropump, the manipulation of bacteria or circulating tumor cells and their interactions with blood cells under the combined effects of ACET electrohydrodynamic (EHD) force and dielectrophoresis (DEP) should be studied in detail for future research in order to achieve the point-of-care diagnostic of septicemia or cancer without blood sample dilution.

\section{CONCLUSIONS}

The ACET phenomenon is demonstrated to be effective for driving non-Newtonian blood flow instead of the mechanical micropump due to the outstanding blood dielectric property which is essential for microfluidic devices for the purpose of realizing point-of-care diagnostic of blood related diseases. In order to clarify and optimize the performance of the ACET blood micropump under several distinct conditions, a 3D GPU-accelerated lattice Boltzmann method is developed, and the Carreau-Yasuda model is applied for characterizing the rheological shear-thinning behavior of whole blood. Based on the modeling, it is found that the ACET blood flow rate increases more rapidly compared with ACET Newtonian flow through scaling law analysis because of the shear rate induced decrement of blood viscosity. Different from electrolyte solution or urine, the dielectric property of blood is highly dependent on the $\mathrm{AC}$ voltage signal frequency, and the current work shows that a relatively low $\mathrm{AC}$ voltage frequency is preferred for highly efficient pumping of ACET blood flow with controlled temperature rise. Under a fixed total electrode area and electrical energy consumption rate, a larger number of shorter electrode pairs are recommended rather than a lesser number of longer electrode pairs for improving the ACET blood flow rate because the larger blood flow shear rate could be generated to decrease blood viscosity by using more short electrode pairs. Furthermore, the ring 
electrodes are proved to be an optimum electrode configuration for ACET blood micropump with limited Joule heating induced temperature rise. Through energy consumption analysis, increasing the AC voltage magnitude is demonstrated to be more economical for enhancing the ACET blood pumping flow rate than adding more electrode pairs inside the microfluidic channel if the temperature rise caused by Joule heating is acceptable.

\section{ACKNOWLEDGMENTS}

The work was supported by the projects of the National Natural Science Foundation of China (NNSFC, No. 51806168) and the China Postdoctoral Science Foundation (No. 2017M623169).

\section{APPENDIX: DIMENSIONLESS GOVERNING EQUATIONS OF ACET BLOOD FLOW}

The governing equations of ACET blood micropump could be nondimensionalized by introducing the following dimensionless parameters:

$x_{d}^{*}=\frac{x}{L_{c}}, y_{d}^{*}=\frac{y}{L_{c}}, V^{*}=\frac{V}{V_{c}}, \Delta T=\frac{\sigma_{r} V_{c}^{2}}{k}, T^{*}=\frac{T-T_{r}}{\Delta T}, u^{*}=\frac{u}{U_{c}}, v^{*}=\frac{v}{U_{c}}$,

$U_{c}=\frac{\varepsilon_{r} \delta_{\sigma} \Delta T V_{c}^{2}}{\mu_{\infty} L_{c}}, p^{*}=\frac{p-p_{r}}{\mu_{\infty} U_{c} / L_{c}}, F_{\boldsymbol{e}}^{*}=\frac{\boldsymbol{F}_{\boldsymbol{e}}}{\varepsilon_{r} V_{c}^{2} \delta_{\sigma} \Delta T / L_{c}^{3}}, R e=\frac{\rho U_{c} L_{c}}{\mu_{\infty}}$.

Then, the dimensionless governing equations of ACET blood flow are given as

$$
\begin{gathered}
\nabla^{* 2} V^{*}=0, \\
\boldsymbol{E}_{r m s}^{*}=-\nabla^{*} V^{*}, \\
J H^{*}=\boldsymbol{E}_{r m s}^{*} \cdot \boldsymbol{E}_{r m s}^{*}, \\
\nabla^{* 2} T^{*}+\left(\boldsymbol{E}_{r m s}^{*} \cdot \boldsymbol{E}_{r m s}^{*}\right)=0, \\
\nabla^{*} \cdot \boldsymbol{u}^{*}=0, \\
\left(\boldsymbol{u}^{*} \cdot \nabla^{*} \boldsymbol{u}^{*}\right)=-\nabla^{*} p^{*}+\left\{1+\left(\frac{\mu_{0}}{\mu_{\infty}}-1\right)\left[1+\left(\frac{\lambda U_{c}}{L_{c}} \dot{\gamma}^{*}\right)^{a}\right]^{\frac{(n-1)}{a}}\right\} \nabla^{* 2} \boldsymbol{u}^{*} \\
+\boldsymbol{F}_{\boldsymbol{e}}^{*}+\boldsymbol{F}_{\boldsymbol{b}}^{*} .
\end{gathered}
$$

The dimensionless AC electrothermal forces are written as

$$
\boldsymbol{F}_{\boldsymbol{e}}^{*}=\frac{1}{2 \alpha}\left(\frac{1-\alpha}{\omega^{2} \tau^{2}+1}\right)\left(\nabla^{*} T^{*} \cdot \boldsymbol{E}_{r m s}^{*}\right) \boldsymbol{E}_{r m s}^{*}-\frac{1}{4 \alpha} \nabla^{*} T^{*}\left|\boldsymbol{E}_{r m s}^{*}\right|^{2} .
$$

The dimensionless buoyancy force is given by

$$
\boldsymbol{F}_{\boldsymbol{b}}^{*}=\frac{\rho_{r} \boldsymbol{g} \beta_{T} \Delta T L_{c}^{2}}{\mu_{\infty} U_{c}} T^{*}
$$

The governing equations of non-Newtonian blood flow driven by ACET forces under different parametric conditions are solved by the lattice Boltzmann method through matching the dimensionless governing parameters.

\section{LATTICE BOLTZMANN METHOD}

\section{a. D3Q7 LBM model for electric potential and temperature}

The D3Q7 model of LBM is used to simulate the electric potential, temperature, and their gradients. In this section, the D3Q7 LBM for temperature field is presented in detail, and the solver for electric potential is the same by setting the source term $\mathrm{JH}$ equal to zero. According to the Bhatnagar-Gross-Krook (BGK) approximation, the evolution equation for the distribution function $g_{i}$ is given as

$$
\begin{aligned}
g_{i}\left(\boldsymbol{x}+\boldsymbol{e}_{i} \Delta t, t+\Delta t\right)= & g_{i}(\boldsymbol{x}, t)-\frac{1}{\tau_{T}}\left[g_{i}(\boldsymbol{x}, t)-g_{i}^{e q}(\boldsymbol{x}, t)\right] \\
& +w_{i} J H(\boldsymbol{x}, t)
\end{aligned}
$$

where $\boldsymbol{x}$ is the location vector on the Cartesian grids, $\Delta t$ is the time step, $\tau_{T}$ is the LBM relaxation time for diffusion equation, $\boldsymbol{e}_{\boldsymbol{i}}$ are the seven velocities in D3Q7 model given as

$$
\left[\boldsymbol{e}_{0}, \boldsymbol{e}_{1}, \boldsymbol{e}_{2}, \boldsymbol{e}_{3}, \boldsymbol{e}_{4}, \boldsymbol{e}_{5}, \boldsymbol{e}_{6}\right]=\left[\begin{array}{ccccccc}
0 & 1 & -1 & 0 & 0 & 0 & 0 \\
0 & 0 & 0 & 1 & -1 & 0 & 0 \\
0 & 0 & 0 & 0 & 0 & 1 & -1
\end{array}\right] c
$$

$c$ is the lattice speed defined as $c=\frac{\Delta x}{\Delta t} \cdot g_{i}^{e q}(\boldsymbol{x}, t)$ is the equilibrium distribution function defined by

$$
g_{i}^{e q}(\boldsymbol{x}, t)=w_{i} T(\boldsymbol{x}, t)
$$

$w_{i}$ is the weight coefficient for D3Q7 model,

$$
w_{i}=\left\{\begin{array}{lc}
0.25, & i=0, \\
0.125, & i=1-6 .
\end{array}\right.
$$

After the collision and streaming steps, the macroscopic temperature $T$ could be calculated as

$$
T=\sum_{i=0}^{6} g_{i}
$$

The boundary conditions derived by Eshraghi et al. ${ }^{42}$ are extended from $2 \mathrm{D}$ to $3 \mathrm{D}$ in the current work to tackle the Dirichlet or Neumann conditions. Besides, the methodology developed by Huang et al. ${ }^{43}$ is also extended from $2 \mathrm{D}$ to $3 \mathrm{D}$ to directly calculate the electric field $(-\nabla V)$ and temperature gradient $(\nabla T)$ using local distribution functions.

\section{b. D3Q19 LBM model for non-Newtonian fluid flow}

The D3Q19 model of LBM is used to simulate the non-Newtonian blood flow in the microchannel. Similarly, the 
BGK collision based evolution equation for density distribution function $f_{i}$ is given as

$$
f_{i}\left(\boldsymbol{x}+\boldsymbol{e}_{i} \Delta t, t+\Delta t\right)=f_{i}(\boldsymbol{x}, t)-\frac{1}{\tau_{f}}\left[f_{i}(\boldsymbol{x}, t)-f_{i}^{e q}(\boldsymbol{x}, t)\right]+F_{i},
$$

where $\tau_{f}$ is the LBM relaxation time for fluid flow, $\boldsymbol{e}_{i}$ is the 19 velocities for D3Q19 model given as

$\boldsymbol{e}_{i}=\left[\begin{array}{ccccccccccccccccccc}0 & 1 & -1 & 0 & 0 & 0 & 0 & 1 & -1 & 1 & -1 & 1 & -1 & 1 & -1 & 0 & 0 & 0 & 0 \\ 0 & 0 & 0 & 1 & -1 & 0 & 0 & 1 & 1 & -1 & -1 & 0 & 0 & 0 & 0 & 1 & -1 & 1 & -1 \\ 0 & 0 & 0 & 0 & 0 & 1 & -1 & 0 & 0 & 0 & 0 & 1 & 1 & -1 & -1 & 1 & 1 & -1 & -1\end{array}\right] c$,

$f_{i}^{e q}(\boldsymbol{x}, t)$ is the equilibrium distribution function which could be computed as

$$
f_{i}^{e q}(\boldsymbol{x}, t)=w_{i} \rho\left[1+\frac{1}{c_{s}^{2}} \boldsymbol{e}_{i} \cdot \boldsymbol{u}+\frac{1}{2 c_{s}^{4}}\left(\boldsymbol{e}_{i} \cdot \boldsymbol{u}\right)^{2}-\frac{1}{2 c_{s}^{2}} \boldsymbol{u} \cdot \boldsymbol{u}\right],
$$

$c_{s}$ is the sound speed defined as $c_{s}=\frac{c}{\sqrt{3}} . w_{i}$ is the weight coefficient for D3Q19 model given by

$$
w_{i}= \begin{cases}1 / 3, & i=0 \\ 1 / 18, & i=1-6 \\ 1 / 36, & i=7-18\end{cases}
$$

The body force $F_{i}$ in Eq. (A15) is given as ${ }^{44}$

$$
F_{i}=w_{i}\left(1-\frac{1}{2 \tau_{f}}\right)\left(\frac{\boldsymbol{e}_{i}-\boldsymbol{u}}{c_{s}^{2}}+\frac{\boldsymbol{e}_{i} \cdot \boldsymbol{u}}{c_{s}^{4}} \boldsymbol{e}_{i}\right) \cdot \boldsymbol{f}
$$

where $f$ is the body force which is the summation of $\mathrm{AC}$

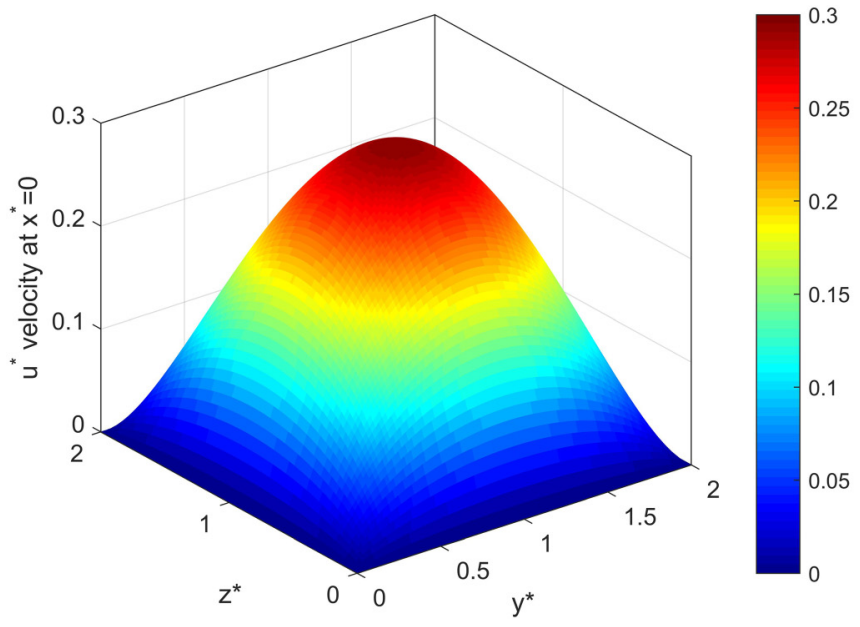

(a) electrothermal force and buoyancy force,

$$
\boldsymbol{f}=\boldsymbol{F}_{\boldsymbol{e}}+\rho_{r} \beta_{T}\left(T-T_{r}\right) \boldsymbol{g} .
$$

The strain rate tensor $S_{i j}$ could be locally calculated at each node during the collision process by ${ }^{30}$

$$
S_{i j}=-\frac{3}{2 \rho c^{2} \tau_{f}} \sum_{k=0} f_{k}^{(1)} \boldsymbol{e}_{k i} \boldsymbol{e}_{k j}
$$

where $f_{k}^{(1)}$ is the nonequilibrium part of the distribution function in the $k$ direction. In the Carreau-Yasuda model of non-Newtonian blood flow, the kinematic viscosity $v$ is given by combining Eqs. (7)-(10) as

$$
v=\frac{\mu_{\infty}+\left(\mu_{0}-\mu_{\infty}\right)\left[1+\left(2 \lambda \sqrt{\sum_{i, j=1}^{3} S_{i j} S_{i j}}\right)^{a}\right]^{(n-1) / a}}{\rho} .
$$

The corresponding relaxation time of LBM $\tau_{f}$ is given as

$$
\tau_{f}=3 v+0.5
$$

The bounce-back scheme is used for the lateral surfaces of the microchannel, and the periodic conditions are applied for the inlet and outlet of the micropump. The density $\rho$ and the macroscopic velocity $\boldsymbol{u}$ are calculated as

$$
\rho=\sum_{i=0}^{18} f_{i}
$$

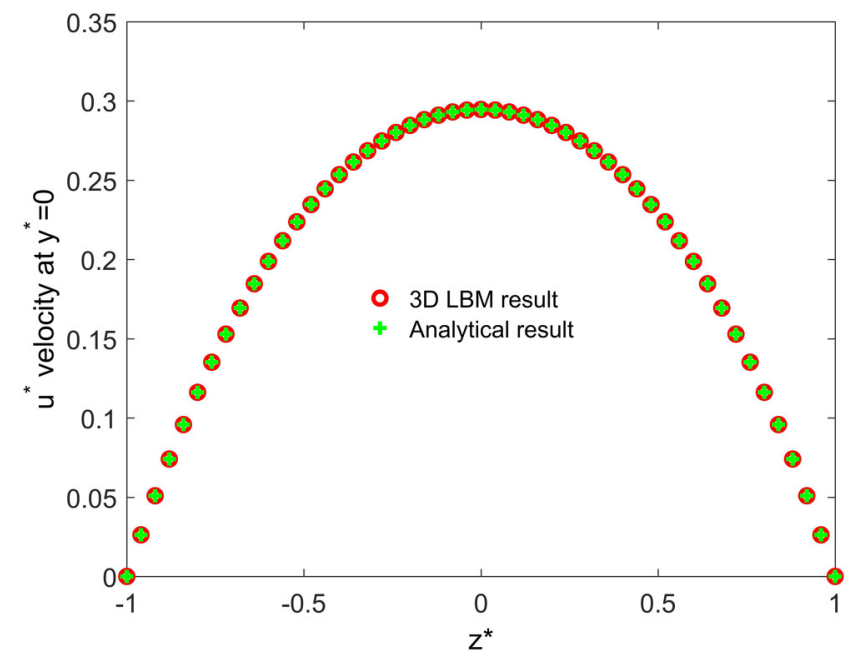

(b)

FIG. 12. D3Q19 LBM fluid solver calibration (a) $u$ velocity profile in the cross section and (b) comparison of LBM results and analytical results. 
TABLE II. Comparison of computational time.

\begin{tabular}{lccc}
\hline \hline Lattice grid numbers & $100 \times 100 \times 100$ & $150 \times 150 \times 150$ & $200 \times 200 \times 200$ \\
\hline CPU intel core i7 8770 s/LBM timestep & 10.742 & 34.525 & 83.174 \\
GPU Quadro GV 100 s/LBM timestep & 0.025 & 0.0664 & 0.1493 \\
Acceleration ratio & 429.68 & 519.95 & 557.09 \\
\hline \hline
\end{tabular}

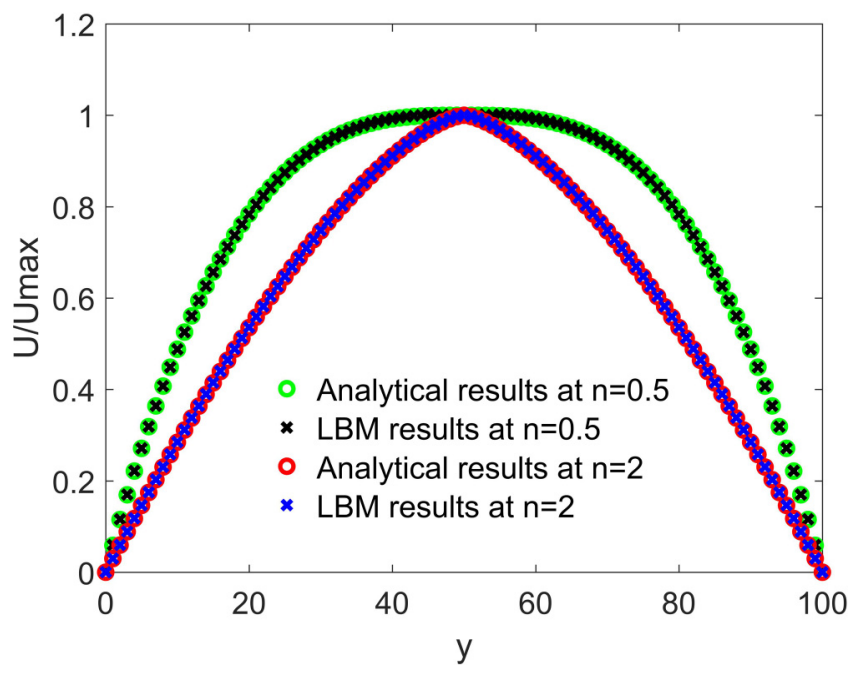

FIG. 13. D3Q19 LBM fluid solver calibration for non-Newtonian flow.

$$
\rho \boldsymbol{u}=\sum_{i=0}^{18} \boldsymbol{e}_{i} f_{i}+\frac{\Delta t}{2} \boldsymbol{f}
$$

\section{CUDA CODE CALIBRATION}

The 3D LBM code with GPU acceleration is calibrated in this section. The Newtonian unidirectional flow in a 3D microchannel with square cross section is firstly presented, and it could be governed by the following Poisson's equation as

$$
\nabla^{2} u^{*}=-1,-1 \leq y^{*} \leq 1,-1 \leq z^{\star} \leq 1,
$$

where $u^{*}=0$ at all the solid boundary surfaces. The analytical solution of this Poisson's equation in a square domain could be found in the reference. ${ }^{45}$ The $u^{*}$ velocity profile in the cross section calculated by the D3Q19 LBM fluid solver is presented in Fig. 12(a), and its comparison with analytical solution is displayed in Fig. 12(b). It is observed that the results of 3D LBM GPU solver are consistent with analytical results using a grid number of $100 \times 100 \times 100$. Similarly, the velocities in the other two directions are also

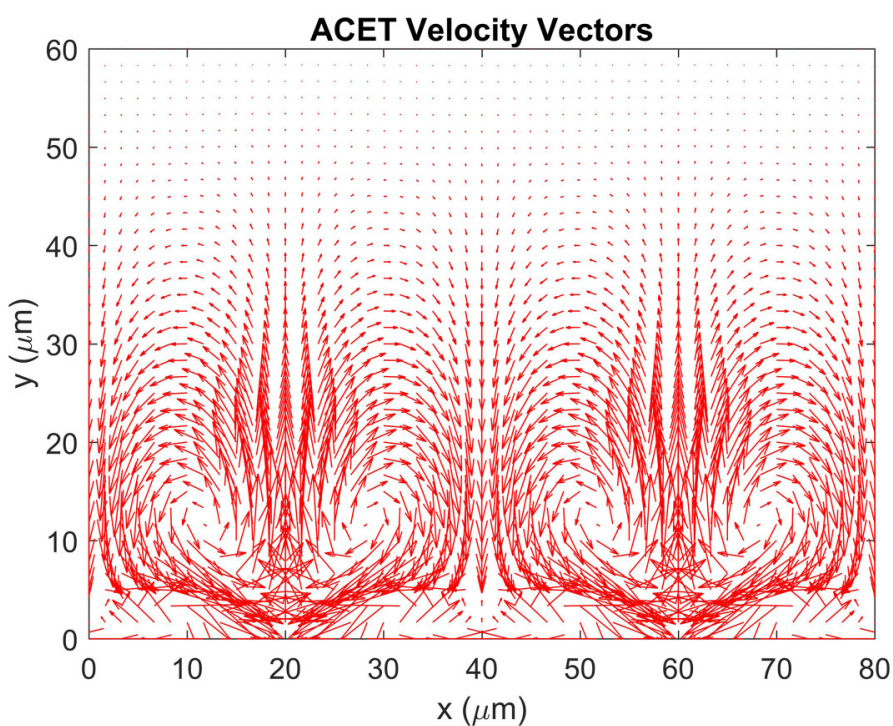

(a)

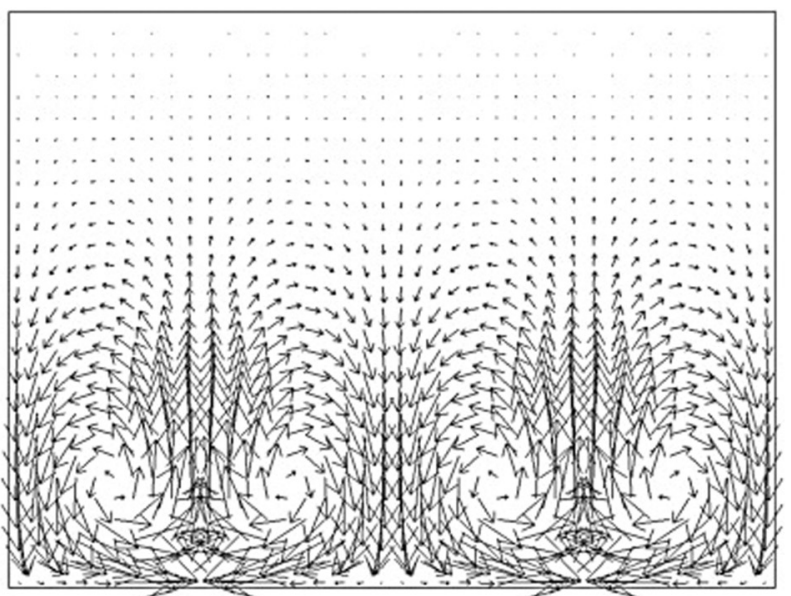

(b)

FIG. 14. Comparison of ACET flow velocity vectors: (a) current work and (b) the results in the reference (Fig. 6) by Cao et al. ${ }^{46}$ 
calibrated. Furthermore, in order to investigate the acceleration performance of GPU computing, the computational time for simulating this unidirectional flow by using the CPU LBM code (not parallel) and the LBM CUDA code is shown in Table II. The results indicate that the computation could be accelerated by 557.09 times at the grid number of $200 \times 200 \times 200$ when the GPU of Quadro GV 100 type is used for parallel computing.

In addition, the D3Q19 LBM solver for non-Newtonian fluid flow is calibrated through the power-law-based two-dimensional Poiseuille flow (making the $z$ direction as periodic) driven by the pressure gradient $G$. The analytical solution for the velocity $u$ in the $x$ direction which is parallel to the axis of the channel is given as

$$
u(y)=\left(\frac{n}{n+1}\right)\left(\frac{G}{\mu_{0}}\right)\left[(H)^{\frac{n+1}{n}}-(H-y)^{\frac{n+1}{n}}\right],
$$

where $H$ is the half height of the fluid channel and the Reynolds number can be defined as

$$
R e_{P L}=\frac{u L}{\mu_{0}}=\frac{G(2 H)^{3}}{8 \mu_{0}} .
$$

In Fig. 13, the normalized velocity of the analytical solutions and the velocity profile calculated by the current 3D LBM CUDA code with a grid number of $7 \times 101 \times 7$ at $R e_{P L}=100$ for the shearthinning $(n=0.5)$ and shear-thicking $(n=2)$ fluids are displayed. It could be observed that the numerical results agree well with the analytical solutions which means that the strain rate tensor $S_{i j}$ computed by Eq. (A21) is accurate. Besides, the same calibration is carried out for the other two flow directions.

As few 3D numerical simulation is carried out for AC electrothermal flow, the current 3D CUDA code is calibrated by comparing the Newtonian fluid velocity vectors and Stokes drag force with the $2 \mathrm{D}$ results in the reference by Cao et al. ${ }^{46}$ As shown in Fig. 14,

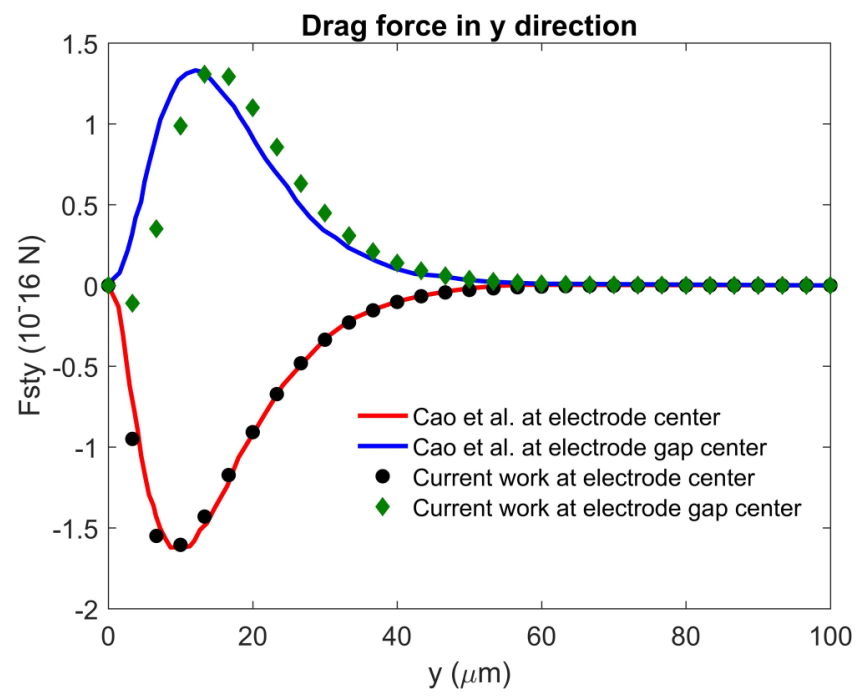

FIG. 15. Comparison of ACET flow velocity vectors: (a) current work and (b) the results in the reference (Fig. 6) by Cao et al. ${ }^{46}$
TABLE III. Boundary conditions for 3D ACET blood micropump.

\begin{tabular}{lccc}
\hline \hline Boundary & $\begin{array}{c}\text { Electric } \\
\text { potential }\end{array}$ & Temperature & $\begin{array}{c}\text { Blood } \\
\text { flow }\end{array}$ \\
\hline Left electrode & $V=+V_{c}$ & $\frac{\partial T}{\partial n}=0$ & $\boldsymbol{u}=0$ \\
Right electrode & $V=-V_{c}$ & $T=T_{r}$ & $\boldsymbol{u}=0$ \\
$\begin{array}{l}\text { Microchannel surfaces } \\
\text { (except the electrode region) }\end{array}$ & $\frac{\partial V}{\partial n}=0$ & $\frac{\partial T}{\partial n}=0$ & $\boldsymbol{u}=0$ \\
$\begin{array}{l}\text { Micropump inlet } \\
\text { Micropump outlet }\end{array}$ & $V=V_{\text {out }}$ & $T=T_{\text {out }}$ & $\boldsymbol{u}=\boldsymbol{u}_{\text {out }}$ \\
\hline \hline
\end{tabular}

by setting the parametric parameters, computational domain geometry, and boundary conditions exactly the same as those in the reference, the ACET flow velocity vectors computed from the current 3D LBM CUDA code through setting the $\mathrm{z}$ direction as periodic are compared with those in the reference. ${ }^{46}$ The results indicate that the velocity patterns from the current work are qualitatively consistent with those of reference paper. In order to make a quantitative comparison for the ACET flow velocity magnitude, the Stokes drag force $F_{S t y}=6 \pi \mu R_{p} u_{y}$ in the vertical direction is plotted in Fig. 15 , where $R_{p}$ is the particle radius and $u_{y}$ is the ACET flow velocity in the vertical direction. From the results, it could be concluded that the current 3D LBM solver for ACET flow is accurate. In addition, the $3 \mathrm{D}$ LBM CUDA code is calibrated for the other two directions as well.

\section{BOUNDARY CONDITIONS AND PHYSICAL PARAMETERS OF ACET BLOOD MICROPUMP}

The boundary conditions for electric potential, temperature, and blood flow in this $3 \mathrm{D}$ ACET blood micropump modeling is summarized in Table III.

The values of physical parameters for current 3D ACET blood micropump modeling are listed in Table IV.

TABLE IV. Physical parameters of 3D ACET blood micropump.

\begin{tabular}{lcc}
\hline \hline Symbol & Value & Unit \\
\hline$V_{c}$ & $0.5-2.5$ & $\mathrm{~V}$ \\
$\omega$ & $10^{6}-10^{7}$ & $\mathrm{~Hz}$ \\
$\sigma_{r}$ & $0.488-1.17$ & $\mathrm{~S} / \mathrm{m}$ \\
$k$ & 0.58 & $\mathrm{~W} /(\mathrm{m} \mathrm{K})$ \\
$\mu_{0}$ & 0.022 & $\mathrm{~Pa} \mathrm{~s}$ \\
$\mu_{\infty}$ & 0.0022 & $\mathrm{~Pa} \mathrm{~s}$ \\
$\lambda$ & 0.11 & $\mathrm{~s}{ }^{-1}$ \\
$a$ & 0.644 & 1 \\
$n$ & 0.392 & 1 \\
$\delta_{\varepsilon}$ & $0.155 \%-0.414 \%$ & $1 /{ }^{\circ} \mathrm{C}$ \\
$\delta_{\sigma}$ & $1.57 \%-1.12 \%$ & $1 /{ }^{\circ} \mathrm{C}$ \\
$\varepsilon_{r}$ & $10^{-7}-3.158 \times 10^{-8}$ & $\mathrm{Farad}^{-8}$ \\
$\rho_{r}$ & 1000 & $\mathrm{~kg} / \mathrm{m}^{3}$ \\
$\beta_{T}$ & $2.07 \times 10^{-4}$ & $1 /{ }^{\circ} \mathrm{C}$ \\
$T_{r}$ & 25 & ${ }^{\circ} \mathrm{C}$ \\
\hline \hline
\end{tabular}




\section{REFERENCES}

'G. M. Whitesides, "The origins and the future of microfluidics," Nature 442, 368-373 (2006).

${ }^{2}$ M. R. Hossan, D. Dutta, N. Islam, and P. Dutta, "Review: Electric field driven pumping in microfluidic device,” Electrophoresis 39, 702-731 (2018).

${ }^{3} \mathrm{~L}$. Li, X. Wang, Q. Pu, and S. Liu, "Advancement of electroosmotic pump in microflow analysis: A review,” Anal. Chim. Acta 1060, 1 (2019).

${ }^{4}$ A. Gonzalez, A. Ramos, H. Morgan, N. G. Green, and A. Castellanos, "Electrothermal flows generated by alternating and rotating electric fields in microsystems," J. Fluid Mech. 564, 415-433 (2006).

${ }^{\mathbf{5}} \mathrm{J}$. Wu, M. Lian, and K. Yang, "Micropumping of biofluids by alternating current electrothermal effects," Appl. Phys. Lett. 90, 234103 (2007).

${ }^{6} \mathrm{E}$. Du and S. Manoochehri, "Enhanced ac electrothermal fluidic pumping in microgrooved channels,” J. Appl. Phys. 104, 064902 (2008).

${ }^{7} \mathrm{E}$. Du and S. Manoochehri, "Microfluidic pumping optimization in microgrooved channels with ac electrothermal actuations," Appl. Phys. Lett. 96, 034102 (2010).

${ }^{8}$ F. J. Hong, J. Cao, and P. Cheng, "A parametric study of AC electrothermal flow in microchannels with asymmetrical interdigitated electrodes," Int. Commun. Heat Mass Transfer 38, 275-279 (2011).

${ }^{9}$ F. J. Hong, F. Bai, and P. Cheng, "Numerical simulation of AC electrothermal micropump using a fully coupled model," Microfluid. Nanofluidics. 13, 411-420 (2012).

${ }^{10} \mathrm{~S}$. J. Williams, "Enhanced electrothermal pumping with thin film resistive heaters," Electrophoresis 34, 1400-1408 (2013).

${ }^{11}$ S. J. Williams and N. G. Green, "Electrothermal pumping with interdigitated electrodes and resistive heaters," Electrophoresis 36, 1681-1689 (2015).

${ }^{12}$ A. Salari, M. Navi, and C. Dalton, "A novel alternating current multiple array electrothermal micropump for lab-on-a-chip applications," Biomicrofluidics 9, 014113 (2015).

${ }^{13}$ R. Zhang, C. Dalton, and G. A. Jullien, "Two-phase AC electrothermal fluidic pumping in a coplanar asymmetric electrode array," Microfluid. Nanofluidics 10, 521-529 (2011).

${ }^{14}$ N. Sasaki, T. Kitamori, and H.-B. Kim, "Fluid mixing using AC electrothermal flow on meandering electrodes in a microchannel," Electrophoresis 33, 2668-2673 (2012).

${ }^{15}$ G. Kunti, A. Bhattacharya, and S. Chakraborty, "Rapid mixing with highthroughput in a semi-active and semi-passive micromixer," Electrophoresis 38, 1310-1317 (2017).

${ }^{16} \mathrm{Y}$. Wu, Y. Ren, and H. Jiang, "Enhanced model-based design of a highthroughput three dimensional micromixer driven by alternating-current electrothermal flow," Electrophoresis 38, 258-269 (2017).

17. Gao et al., "Hybrid electrokinetic manipulation in high-conductivity media," Lab Chip 11, 1770-1775 (2011).

${ }^{18}$ Q. Lang, Y. Wu, Y. Ren, Y. Tao, L. Lei, and H. Jiang, "AC electrothermal circulatory pumping chip for cell culture," Appl. Mater. Interfaces 7, 26792-26801 (2015).

${ }^{19}$ A. Kale et al., "Electrothermal enrichment of submicron particles in an insulator-based dielectrophoretic microdevice," Electrophoresis 39, 887-896 (2018).

${ }^{20} \mathrm{~N}$. Sato et al., "Numerical study of particle-fluid flow under AC electrokinetics in electrode-multilayered microfluidic device," IEEE Trans. Biomed. Eng. 66, 453-463 (2019).

${ }^{\mathbf{2 1}} \mathrm{H}$. Sun et al., "Continuous particle trapping, switching, and sorting utilizing a combination of dielectrophoresis and alternating current electrothermal flow," Anal. Chem. 91, 5729-5738 (2019).

${ }^{22} \mathrm{Q}$. Ren, "Cell transport and suspension in high conductivity electrothermal flow with negative dielectrophoresis by immersed boundary-lattice Boltzmann method," Int. J. Heat Mass Transfer 128, 1229-1244 (2019).

${ }^{23} \mathrm{Q}$. Ren, "Bioparticle delivery in physiological conductivity solution using AC electrokinetic micropump with castellated electrodes," J. Phys. D Appl. Phys. 51, 465401 (2018).
${ }^{\mathbf{2 4}} \mathrm{M}$. Antfolk and T. Laurell, "Continuous flow microfluidic separation and processing of rare cells and bioparticles found in blood-A review," Anal. Chim. Acta 965, 9-35 (2017).

${ }^{\mathbf{2 5}}$ J. M. Jackson, M. A. Witek, J. W. Kamande, and S. A. Soper, "Materials and microfluidics: Enabling the efficient isolation and analysis of circulating tumour cells," Chem. Soc. Rev. 46, 4245-4280 (2017).

${ }^{\mathbf{2 6}} \mathrm{Q}$. Ren, "Investigation of pumping mechanism for non-Newtonian blood flow with AC electrothermal forces in a microchannel by hybrid boundary element method and immersed boundary-lattice Boltzmann method," Electrophoresis 39, 1329-1338 (2018).

${ }^{\mathbf{2 7}}$ S. Chen and G. D. Doolen, "Lattice Boltzmann method for fluid flows," Annu. Rev. Fluid Mech. 30, 329-364 (1998).

${ }^{28}$ C. K. Aidun and J. R. Clausen, "Lattice-Boltzmann method for complex flows,” Annu. Rev. Fluid Mech. 42, 439-472 (2010).

29. Zhang, "Lattice Boltzmann method for microfluidics: Models and applications," Microfluid. Nanofluid. 10, 1-28 (2011).

${ }^{30}$ A. M. Artoli, Mesoscopic Computational Haemodynamics (Ponsen \& Looijen, Wageningen, 2003).

${ }^{31}$ J. Boyd and J. M. Buick, "Analysis of the Casson and Carreau-Yasuda non-Newtonian blood models in steady and oscillatory flows using the lattice Boltzmann method," Phys. Fluids 19, 093103 (2007).

${ }^{32} \mathrm{Q}$. Ren and C. L. Chan, "GPU accelerated numerical study of PCM melting process in an enclosure with internal fins using lattice Boltzmann method," Int. J. Heat Mass Transfer 100, 522-535 (2016).

${ }^{33} \mathrm{Q}$. Ren and C. L. Chan, "Numerical study of double-diffusive convection in a vertical cavity with Soret and Dufour effects by lattice Boltzmann method on GPU,” Int. J. Heat Mass Transfer 93, 538-553 (2016).

${ }^{34} \mathrm{Q}$. Ren, F. Meng, and P. Guo, “A comparative study of PCM melting process in a heat pipe-assisted LHTES unit enhanced with nanoparticles and metal foams by immersed boundary-lattice Boltzmann method at pore-scale," Int. J. Heat Mass Transfer 121, 1214-1228 (2018).

${ }^{35}$ Q. Ren, Y.-L. He, K.-Z. Su, and C. L. Chan, "Investigation of the effect of metal foam characteristics on the PCM melting performance in a latent heat thermal energy storage unit by pore-scale lattice Boltzmann modeling," Numer. Heat Transfer Part A: Appl. 72, 745-764 (2017).

${ }^{36}$ A. Ramos, H. Morgan, N. G. Green, and A. Castellanos, "AC electrokinetics: A review of forces in microelectrode structures,” J. Phys. D Appl. Phys. 31, 2338-2353 (1998).

${ }^{37}$ Q. Ren, C. L. Chan, and A. L. Arvayo, "A numerical study of $2 \mathrm{D}$ electrothermal flow using boundary element method," Appl. Math. Model. 39, 2777-2795 (2015).

${ }^{38}$ S. Loire, P. Kauffmann, I. Mezic, and C. D. Meinhart, "A theoretical and experimental study of ac electrothermal flows,” J. Phys. D Appl. Phys. 45, 185301 (2012).

${ }^{39}$ Y. Lu, Q. Ren, T. Liu, S. L. Leung, V. Gau, J. C. Liao, C. L. Chan, and P. K. Wong, "Long-range electrothermal fluid motion in microfluidic systems," Int. J. Heat Mass Transfer 98, 341-349 (2016).

${ }^{40}$ S. Abdalla, S. S. Al-ameer, and S. H. Al-Magaishi, "Electrical properties with relaxation through human blood," Biomicrofluidics 4, 034101 (2010).

${ }^{41}$ F. Jaspard and M. Nadi, "Dielectric properties of blood: An investigation of temperature dependence,” Phys. Meas. 23, 547-555 (2002).

${ }^{\mathbf{4 2}} \mathrm{M}$. Eshraghi and S. D. Felicelli, "An implicit lattice Boltzmann model for heat conduction with phase change,” Int. J. Heat Mass Transfer 55, 2420-2428 (2012).

${ }^{43} \mathrm{R}$. Huang and $\mathrm{H}$. Wu, "Multiblock approach for the passive scalar thermal lattice Boltzmann method,” Phys. Rev. E 89, 043303 (2014).

${ }^{44}$ Z. Guo, C. Zheng, and B. Shi, "Discrete lattice effects on the forcing term in the lattice Boltzmann method,” Phys. Rev. E 65(4), 046308 (2002).

${ }^{45}$ H. C. Elman, D. J. Silvester, and A. J. Wathen, Finite Elements and Fast Iterative Solvers With Applications in Incompressible Fluid Dynamics (Oxford University Press, Oxford, 2005), p. 11.

${ }^{46}$ J. Cao, P. Cheng, and F. Hong, "A numerical analysis of forces imposed on particles in conventional dielectrophoresis in microchannels with interdigitated electrodes," J. Electrostatics 66, 620-626 (2008). 